\title{
SPM response to tide and river flow in the hyper-turbid Ems River
}

\author{
Johan C. Winterwerp ${ }^{1,2}$ - Julia Vroom ${ }^{2}$ - Zheng-B. Wang ${ }^{2,3} \cdot$ Martin Krebs $^{4}$. \\ Erik C.M. Hendriks ${ }^{3}$ • Dirk S. van Maren ${ }^{2,3}$ - Kerstin Schrottke ${ }^{5}$. \\ Christine Borgsmüller ${ }^{6}$ • Andreas Schöl ${ }^{7}$
}

Received: 12 August 2016 / Accepted: 27 February 2017 /Published online: 28 March 2017

(C) The Author(s) 2017. This article is published with open access at Springerlink.com

\begin{abstract}
In this paper, we analyse the behaviour of fine sediments in the hyper-turbid Lower Ems River, with focus on the river's upper reaches, a stretch of about $25 \mathrm{~km}$ up-estuary of Terborg. Our analysis is based on long records of suspended particulate matter (SPM) from optical backscatter (OBS) measurements close to the bed at seven stations along the river, records of salinity and water level measurements at these stations, acoustic measurements on the vertical mud structure just up-estuary of Terborg and oxygen profiles in the lower $3 \mathrm{~m}$ of the water column close to Leerort and Terborg. Further, we use cross-sectionally averaged velocities computed with a calibrated numerical model. Distinction is made between four timescales, i.e. the semi-diurnal tidal timescale, the springneap tidal timescale, a timescale around an isolated peak in river flow (i.e. about 3 weeks) and a seasonal timescale. The data suggest that a pool of fluid/soft mud is present in these
\end{abstract}

Responsible Editor: Emil Vassilev Stanev

Johan C. Winterwerp

j.c.winterwerp@tudelft.nl

Julia Vroom

Julia.Vroom@deltares.nl

Zheng-B. Wang

Zheng.Wang@ deltares.nl

Martin Krebs

johann-martin.krebs@wsv.bund.de

Erik C.M. Hendriks

H.C.M.Hendriks@tudelft.nl

Dirk S. van Maren

Bas.vanMaren@deltares.nl

Kerstin Schrottke

ks@gpi.uni-kiel.de upper reaches, from up-estuary of Papenburg to a bit downestuary of Terborg. Between Terborg and Gandersum, SPM values drop rapidly but remain high at a few gram per litre. The pool of fluid/soft mud is entrained/mobilized at the onset of flood, yielding SPM values of many tens gram per litre. This suspension is transported up-estuary with the flood. Around high water slack, part of the suspension settles, being remixed during ebb, while migrating down-estuary, but likely not much further than Terborg. Around low water slack, a large fraction of the sediment settles, reforming the pool of fluid mud. The rapid entrainment from the fluid mud layer after low water slack is only possible when the peak flood velocity exceeds a critical value of around $1 \mathrm{~m} / \mathrm{s}$, i.e. when the stratified water column seems to become internally supercritical. If the peak flood velocity does not reach this critical value, f.i. during neap tide, fluid mud is not entrained up to the

Christine Borgsmüller

Borgsmueller@bafg.de

Andreas Schöl

Schoel@bafg.de

Environmental Fluid Mechanics, Delft University of Technology, PO Box 5048, 2600 Delft, GA, The Netherlands

2 Deltares, Delft, The Netherlands

3 Delft University of Technology, Delft, The Netherlands

4 Ems Waterway Administration, Emden, Germany

5 University of Kiel, Kiel, Germany

6 Department of Quantitative Hydrology, Federal Institute of Hydrology, Koblenz, Germany

7 Department of Ecology, Federal Institute of Hydrology, Koblenz, Germany 
OBS sensors. Thus, it is not classical tidal asymmetry, but the peak flood velocity itself which governs the hyper-turbid state in the Lower Ems River. The crucial role of river flow and river floods is in reducing these peak flood velocities. During elongated periods of high river flow, in e.g. wintertime, SPM concentrations reduce, and the soft mud deposits consolidate and possibly become locally armoured as well by sand washed in from the river. We have no observations that sediments are washed out of the hyper-turbid zone. Down-estuary of Terborg, where SPM values do not reach hyper-turbid conditions, the SPM dynamics are governed by classical tidal asymmetry and estuarine circulation. Hence, nowhere in the river, sediments are flushed from the upper reaches of the river into the Ems-Dollard estuary during high river flow events. However, exchange of sediment between river and estuary should occur because of tide-induced dispersion.

Keywords Tidal asymmetry $\cdot$ Hyper-turbid sediment concentrations $\cdot$ Entrainment

\section{Introduction}

The Lower Ems River ("Unterems") forms the most upstream part of the Ems-Dollard estuary (see Fig. 1). This tidal river measures about $65 \mathrm{~km}$ from Herbrum weir to the river's mouth at Knock, located just down-estuary of a large tidal bay, known as the Dollard. Up-river, near Herbrum, the width of the river measures about $60 \mathrm{~m}$, increasing to about $120 \mathrm{~m}$ near Papenburg and around $600 \mathrm{~m}$ near the river's mouth. The Dollard is a shallow and very muddy bay at the head of the Ems-Dollard estuary, which itself is mainly sandy, apart from muddy fringes along its banks. Suspended particulate matter (SPM) concentrations read a few $100 \mathrm{mg} / \mathrm{L}$. The Ems-Dollard estuary forms part of the Wadden Sea, whose bed is also mainly sandy. This estuary is located between The Netherlands and Germany. However, the Ems River is on German territory.

Generally, the Ems's river discharge varies between around 20 and $400 \mathrm{~m}^{3} / \mathrm{s}$, with an average of around $100 \mathrm{~m}^{3} / \mathrm{s}$ and exceptional peak values as high as $1200 \mathrm{~m}^{3} / \mathrm{s}$ (Van Leussen 1994). This river flow is measured at Versen, about $40 \mathrm{~km}$ upstream op Herbrum. At mean river flow, salty water may penetrate up to Terborg, and at elongated periods of low river flow, salty water is even measured around Leerort. The tidal range varies from around $2.5 \mathrm{~m}$ in the Wadden Sea (near Borkum) amplifying within the river to values over $5 \mathrm{~m}$ at spring tides.

The Ems-Dollard estuary in general and the Lower Ems River in particular have become progressively more turbid, with mean near-surface SPM concentrations up to $1 \mathrm{~g} / \mathrm{L}$ over almost its entire length (de Jonge et al. 2014), while Talke et al. (2007), Papenmeier et al. (2013) and Held et al. (2013) measured concentrations of fine suspended sediment over tens
Fig. 1 The upper reaches of the Ems-Dollard estuary - the current analysis focuses on the upper reaches of the Lower Ems River ("Unterems"), i.e. between Terborg and Papenburg (about $25 \mathrm{~km})$

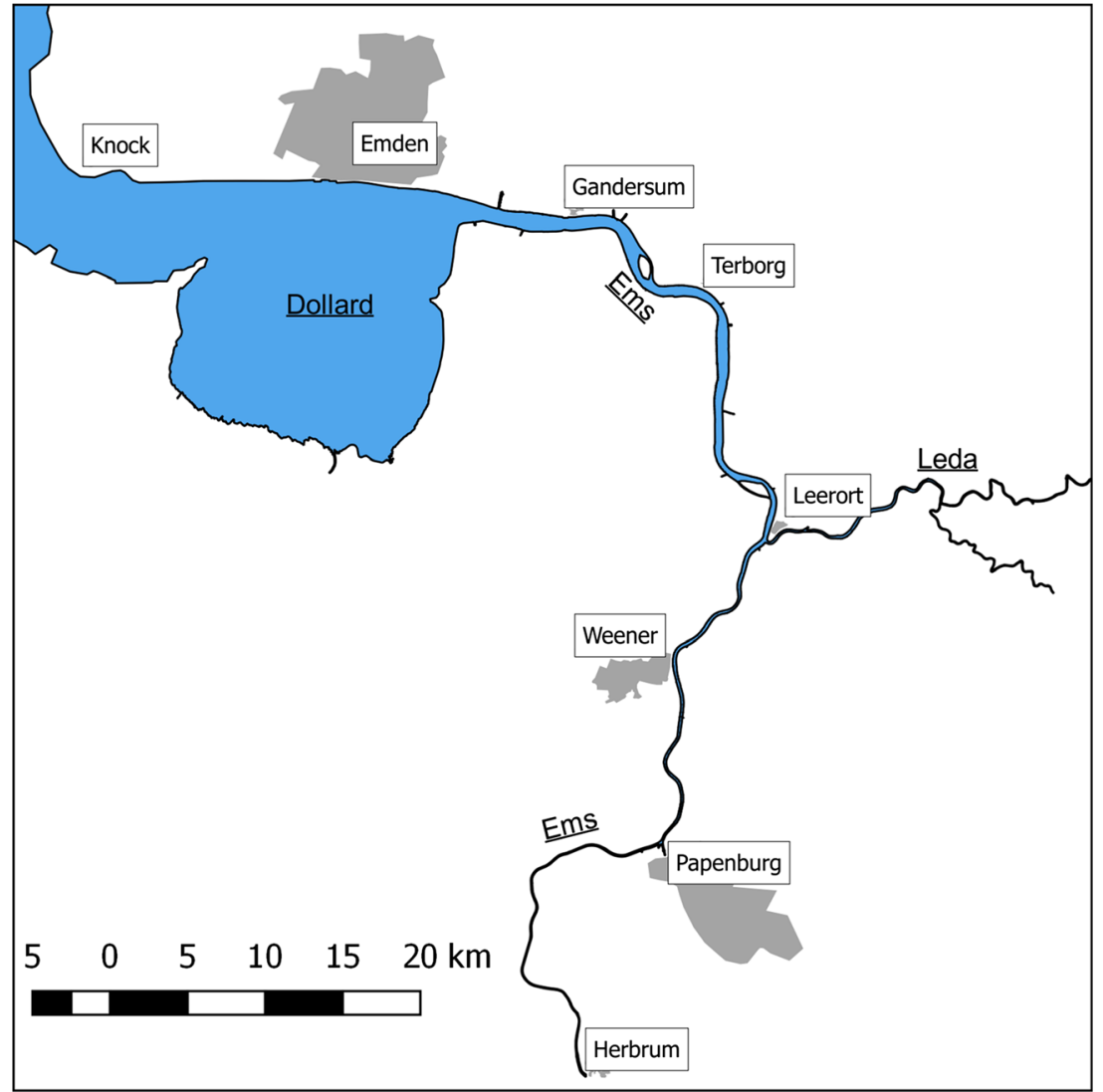


of grams per litre lower in the water column. The large increase in turbidity levels over the last decades has been attributed to the following:

1. A reduction in the amount of sediment taken out of the Lower Ems River. Between 1960 and 1993, about 1.8 Mton of sediment (mainly mud) was removed from the Port of Emden and brought on land. This removal stopped in 1994, and Van Maren et al. (2015) suggest that this triggered the increase in SPM in the river.

2. An ongoing deepening of the river (e.g. de Jonge et al. 2014; Winterwerp 2011; Winterwerp and Wang 2013; Winterwerp et al. 2013). This is even more remarkable, as the sediments dredged from the river during the ongoing maintenance works are deposited well outside the river system, e.g. 15-20 km off the river mouth.

Note that today, still about 0.8 Mton of mud is removed from the river every year and brought on land, while the average total amount of mud in the river is estimated at 1 Mton (Van Maren et al. 2016).

The high SPM concentrations at various measuring stations appear to correlate inversely with river flow, resulting in a profound seasonal variation in SPM values at, for instance, Papenburg (e.g. Fig. 2). However, also, short-term variations in river flow, of the order of days, show a large response in SPM concentrations, virtually along the entire river, as depicted in Fig. 3.
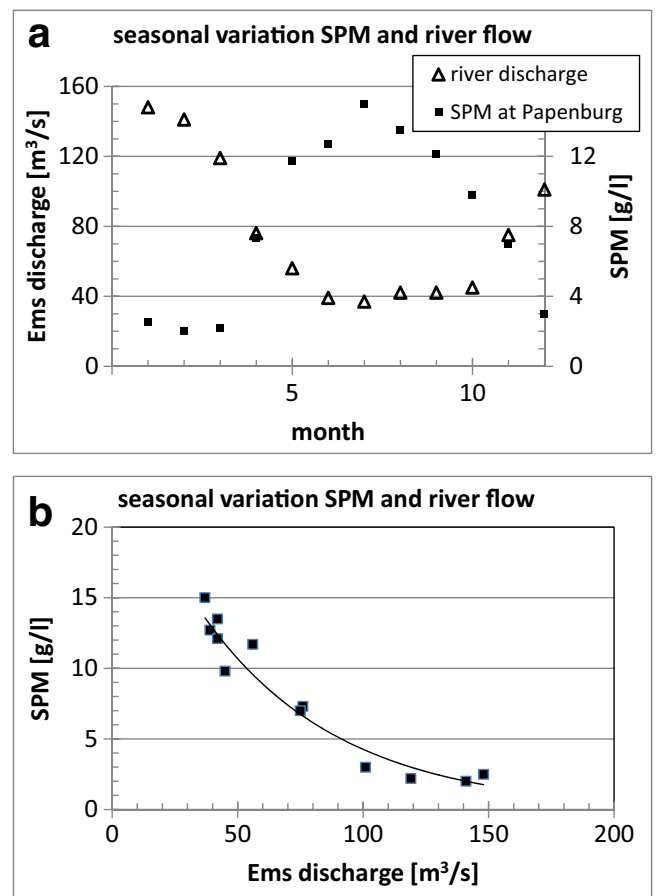

Fig. 2 Monthly mean SPM concentrations measured at Papenburg as a function of river flow, data averaged over the period 2007-2013. These graphs show an inverse relation between SPM and river flow, suggesting flushing of the river at higher river flows
The objective of this paper is assessing the behaviour of suspended sediment (SPM) in the Lower Ems River ("Unterems") in response to variations in river flow and tide, with focus on its upper reaches, i.e. up-estuary of Terborg, where the effects of estuarine circulation are small or even absent. This behaviour is evaluated at four different timescales:

1. The semi-diurnal tidal timescale,

2. The spring-neap time cycle,

3. An arbitrary timescale around a short duration peak in river flow in summer time when the river flow is otherwise small (i.e. a timescale of a few weeks, yet larger than the spring-neap cycle),

4. A seasonal timescale (i.e. half-yearly variations).

We postulate that the major effect of variations in river discharge is through its modification of the tidal asymmetry. Because of the trumpet-shaped plan form of the river, fresh river water-induced velocities become smaller down-estuary. Then, river-induced flushing becomes ineffective. Moreover, because of the large sediment-induced stratification in the river, fresh water would mainly flow over the mud, reducing flushing effects further.

Our analysis is mainly based on over 2 years of continuous SPM and salinity data (mid 2009 till end 2011) at seven stations along the river (e.g. Table 1, Fig. 4), but we focus on the 2010 data, as in this year, the river flow remained small during two months. The SPM data were obtained with OBS sensors of type Solitax by Hach Lange mounted 1-2 $\mathrm{m}$ above the bed and collected every $5 \mathrm{~min}$. The OBS sensors were each calibrated against water samples, as described by Habermann (2006).

Data on tidal elevation at these stations and on river flow at Herbrum (in fact $40 \mathrm{~km}$ further upstream, i.e. Versen) were also available for this period. Two velocity measurements on two sequential days are also used for our analysis, completed with cross-sectional averaged velocities computed with a calibrated numerical model, i.e. Delft3D. Additionally, we analyse data on oxygen levels measured near Leerort in summer 2014. Furthermore, data from a parametric echo sounder system (SES 2000 by Innomar Technology GmbH), obtained over a longitudinal profile (see Schrottke \& Bartholomä 2008) downstream of Leer, are presented to study short-term SPM variations (see Sect. 4). Further information on the system's configuration is given by Schrottke et al. (2006).

In Sect. 2, we discuss the peculiarities of the hydrodynamics in the Ems River and its synchronicity. Also, we introduce the Delft3D model and the computed flow velocities as a function of tidal elevation, which are used to complete the limited velocity measurements. This model is exclusively used as an aid in analysing the observations. In the following, we argue that the phasing of the tidal measurements can be used as a proxy for the phasing of the tidal velocity. Further, 
Fig. 3 Variation of SPM concentrations measured in 2010 in the Lower Ems River in response to river discharge with emphasis on the decrease in SPM with increasing river flow, either during short peaks or elongated periods. The lower graph depicts the flow rate in 2010, while the upper graph depicts SPM values measured at eight stations in the river. Further to Fig. 2, also these graphs suggest SPM flushing out of the river with increasing river flows
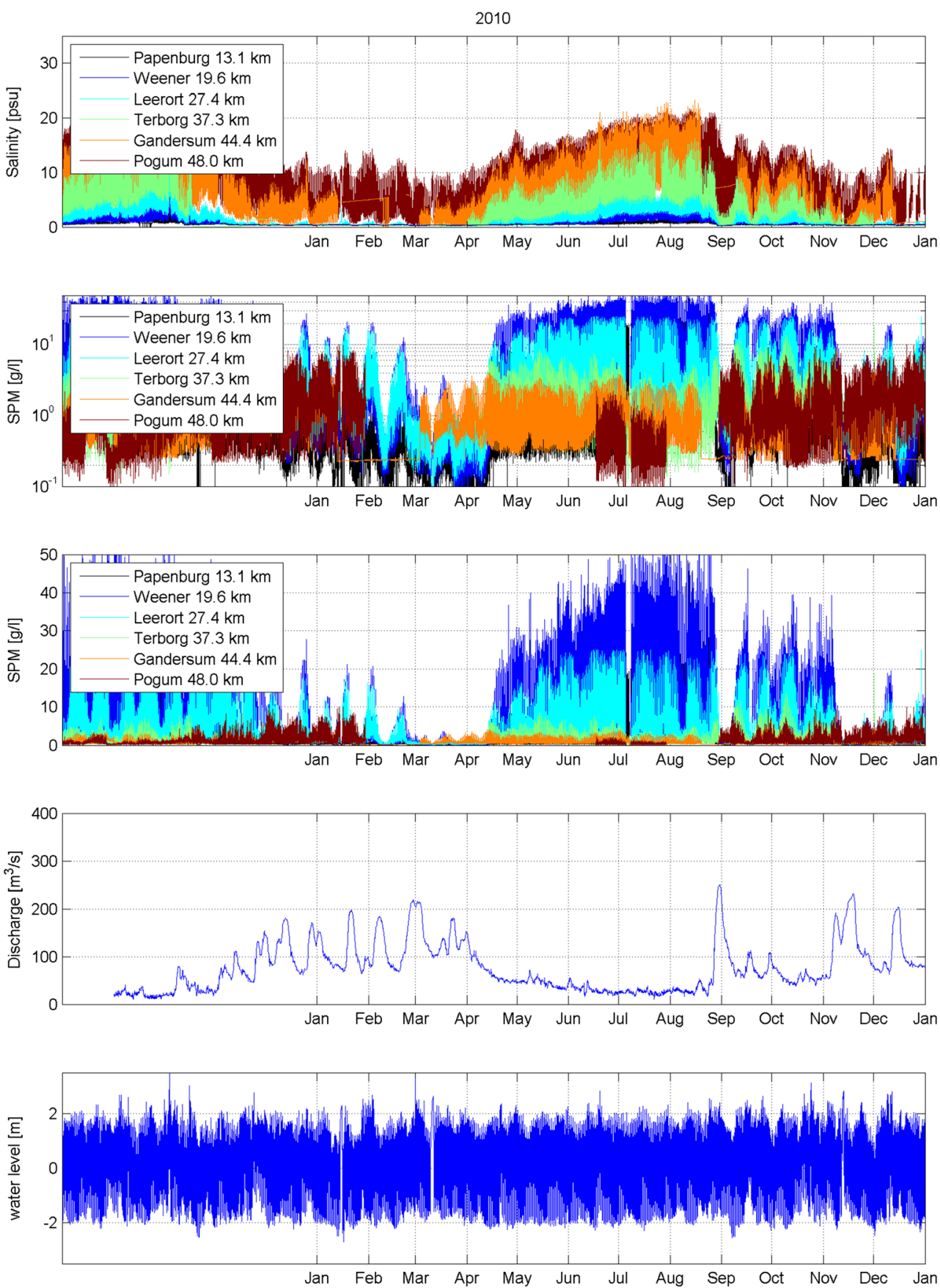

we discuss the classical concept of asymmetry in peak velocity, how this asymmetry controls net sediment transport and how that asymmetry is affected by river flow. In Sect. 3, we analyse the river's response to the tide; i.e. we discuss SPM variations on the timescale of the semidiurnal tide, whereas in Sect. 4, we discuss spring-neap tide effects. Then, we focus on the role of the river flow, with SPM response to short-term variations in river flow in Sect. 5, while seasonal effects are discussed in Sect. 6. Finally, in Sect. 7, we present a discussion of our analyses and summarize our conclusions.

\section{The upper Ems River-synchronicity and tidal asymmetry}

Figures 5a and 6 present two recordings on depth-averaged flow velocity in conjunction with the tidal elevation. Both figures show that elevation and velocity are (almost) $90^{\circ}$ out of phase; i.e. high water slack (HWS) and high water (HW) and low water slack (LWS) and low water (LW) occur (almost) at the same time. Also, over time, the tidal amplitude became almost constant along the river, in response to ongoing deepening of the river (e.g. Krebs and Weilbeer 2008). 
Table 1 Measuring stations along the Lower Ems River, location of oxygen sensors and location of OBS sensors above the bed

\begin{tabular}{lll}
\hline Measuring station & Distance from Herbrum $(\mathrm{km})$ & \\
\hline 1. Papenburg (P) & 13.9 & OBS 2.0 mab \\
2. Weener (W) & 19.6 & OBS 1.5 mab \\
Middelstenborgum & 24.4 & 6 oxygen sensors \\
3. Leerort (L) & 27.4 & OBS 1.5 mab \\
4. Terborg (T) & 37.3 & OBS 1.0 mab and 6 oxygen sensors \\
5. Gandersum (G) & 44.4 & OBS \\
6. Pogum (Po) & 48.0 & OBS \\
7. Emden (E) & 53.9 & OBS 1.5 mab \\
\hline
\end{tabular}

Note that the exact bed level is difficult to define owing to the fluid mud occurrences, in particular in the upper reaches of the river

mab meters above bed
Winterwerp and Wang (2013) showed that these observations can only be explained by a strong reduction in the effective hydraulic drag in the Ems River (see also Friedrichs 2010 and Dronkers 2005) over that time period. We refer to synchronicity. To sustain this synchronic behaviour further, we have analysed the tide and salinity distribution in the Appendix. An important assumption in this analysis is that maximum and minimum salinities $S_{\max }$ and $S_{\min }$ occur at HWS and LWS, respectively. This synchronicity is explicitly used in the analyses in the next section of our paper; i.e. that HW and HWS, and LW and LWS occur synchronously, thus $t_{\mathrm{HW}}=t_{\mathrm{HWS}}$ and $t_{\mathrm{LW}}=t_{\mathrm{LWS}}$. Yet, the tidal wave is still progressive, with a travel time between Knock and Papenburg of about $5 \mathrm{~h}$.

The second important observation from Figs. 5a and 6 (see also Fig. 31 (A.2)) is the large asymmetry in the tidal velocities. Directly after LWS, the flow velocity increases rapidly, while reducing rapidly again towards HWS. Ebb velocities build up much slower and are much lower as well (30$50 \%$ ). As a result, also the rising water period is much shorter than the falling water period - because of the synchronicity of the river, these periods correspond to flooding and ebbing, respectively. It is well acknowledged that such tidal asymmetry yields flood-dominant conditions for (fine) sediment transport (e.g. Groen 1967; Friedrichs 2010; Dronkers 2005).

We have analysed the tidal asymmetry in the Ems River further with a hydrodynamic model, based on the Delft3D software (Lesser et al. 2004). The model was calibrated against measured data, showing proper simulation of the tidal propagation in the Ems River (Van Maren et al. 2015). The model domain covers the Ems River from Knock in the northwest to the weir at Herbrum in the south. The grid cell size varies from $35 \times 70 \mathrm{~m}^{2}$ upstream of Leerort to $100 \times 300 \mathrm{~m}^{2}$ in the Emder Fahrwasser, and the model has ten equidistant $\sigma$ layers in the vertical. The model bathymetry is interpolated from measurements in 2005, and the bed roughness is prescribed with a low Manning coefficient of $0.01 \mathrm{~s} / \mathrm{m}^{1 / 3}$, accounting for the high contents of soft mud in the river. The model is forced with observed water levels at Knock and a constant discharge at the weir in Herbrum. Salinity, suspended sediments nor fluid mud is explicitly modelled; hence, the computed vertical velocity profiles cannot reflect the effects of (sediment-induced) stratification. The computed velocity profiles are therefore expected to deviate from the actual vertical profiles in the river. However, depth-averaged flow velocities are well reproduced, as shown in Fig. 5b. In particular, the phasing of LWS and HWS with respect to low and HW and the ratio between peak flood and peak ebb velocities are in line with the observations, which is a key aspect for the analyses in the current paper. Note that the periods of observations and simulations differ, as Fig. 5b only aims at showing that phasing and asymmetry are well captured by the model.

Eight Delft3D simulations were carried out using the measured water levels at Knock for January 2005. For each simulation, a constant river discharge at Herbrum is prescribed, i.e. $Q_{\text {riv }}=0,10,50,100,150,200,300$ and
Fig. 4 Measuring stations along the Lower Ems River for SPM and oxygen. Also given by the grey band are the locations of the $10 \mathrm{~g} / \mathrm{L} \mathrm{SPM}$ value at HWS and LWS, measured by Talke et al. (2007) on 2 August 2006, after more than 2 months of low river flow $\left(\sim 30 \mathrm{~m}^{3} / \mathrm{s}\right)$

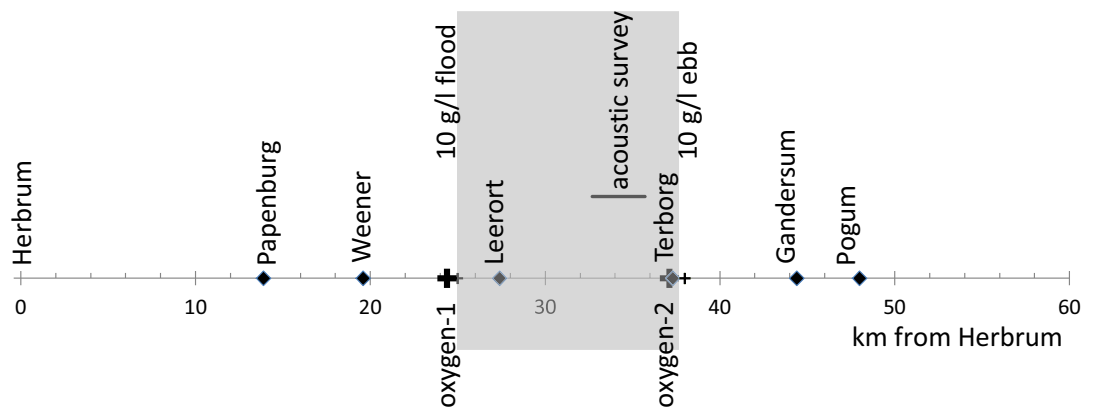


Fig. 5 a Measurements of tidal elevation and velocity on 25 and 26 February 2009, at $31 \mathrm{~km}$, just down-estuary of Leerort in left outer bend of the river; Feb 27 is springtide (after Wang 2010; acknowledgment, M. Becker).

The first major observation is that LWS and LW, and HWS and HW, respectively, occur

simultaneously (i.e. $90^{\circ}$ phase difference). The second major observation is that peak flood velocities are much larger than the peak ebb velocities. b Computed tidal level and computed flow velocity (cross-sectional average), September 2010. Comparison of a, b shows that the Delft3D computations depict the same $90^{\circ}$ phase difference between tide and velocity and the strong asymmetry between peak flood and peak ebb velocity
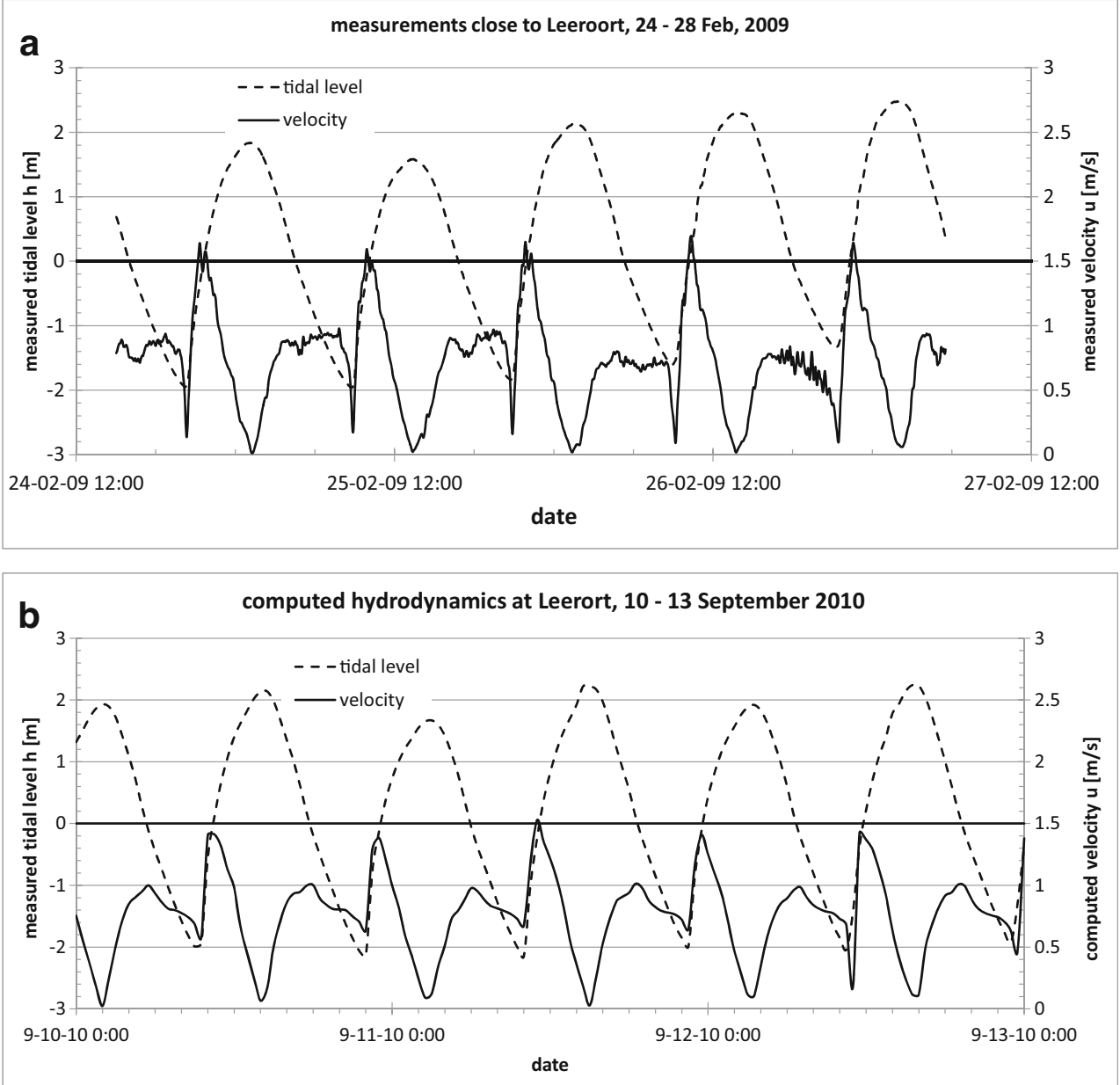

$400 \mathrm{~m}^{3} / \mathrm{s}$. Obviously, with increasing river discharges, ebb velocities increase, whereas flood velocities decrease, while this effect is stronger in the narrower parts of the river, i.e. upestuary. In the following, we argue that (peak) flood velocities dictate the SPM behaviour in the Ems River. Therefore, we analyse the effect of river flow on peak flood velocities first (see Fig. 7). This figure shows a strong decrease in computed mean peak velocities $\left\langle\hat{u}_{f l}\right\rangle$ (i.e. averaged over January 2010) in the upper part of the river, while further down-estuary, this decrease is smaller. It is remarkable that the peak velocities at Leerort are about 10\% smaller than at Weener and Papenburg. This irregular behaviour is fully explained by the larger cross section at Leerort, which is likely the result of the river's tributary at that location, the Leda.
Fig. 6 Tidal elevation and depthmean velocity at Weener measured 20-22 February 2014 similar observations w.r.t. phasing and asymmetry as in Fig. 6

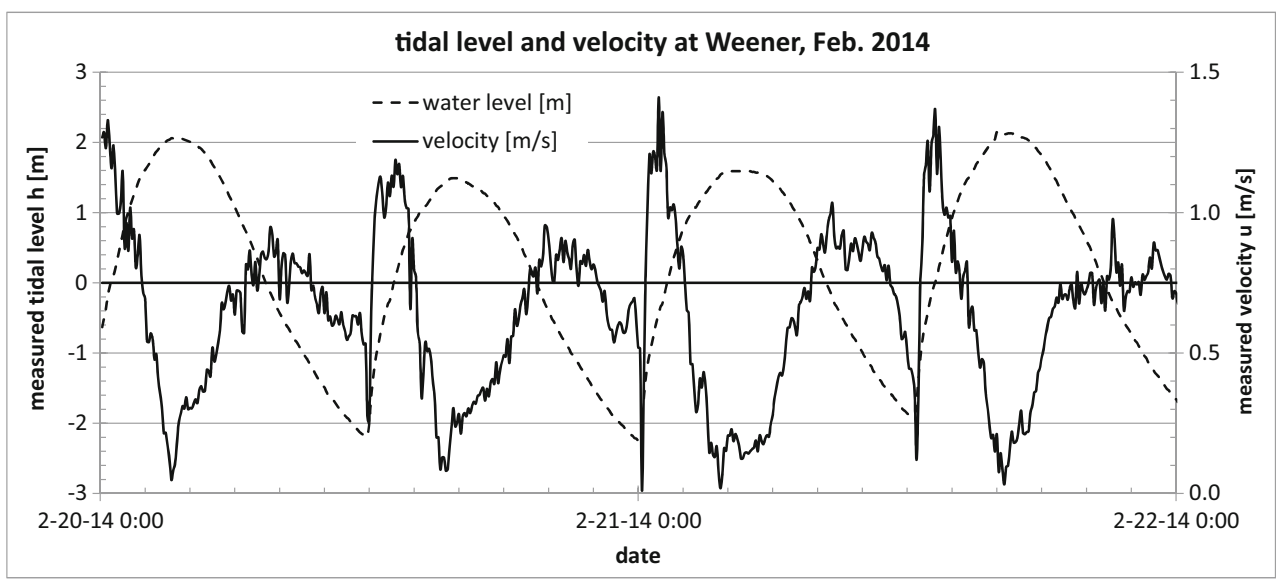


Fig. 7 Longitudinal variation of mean peak flood velocity as a function of river flow (mean-tide conditions). Capital letters depict observation stations, e.g. Table 1

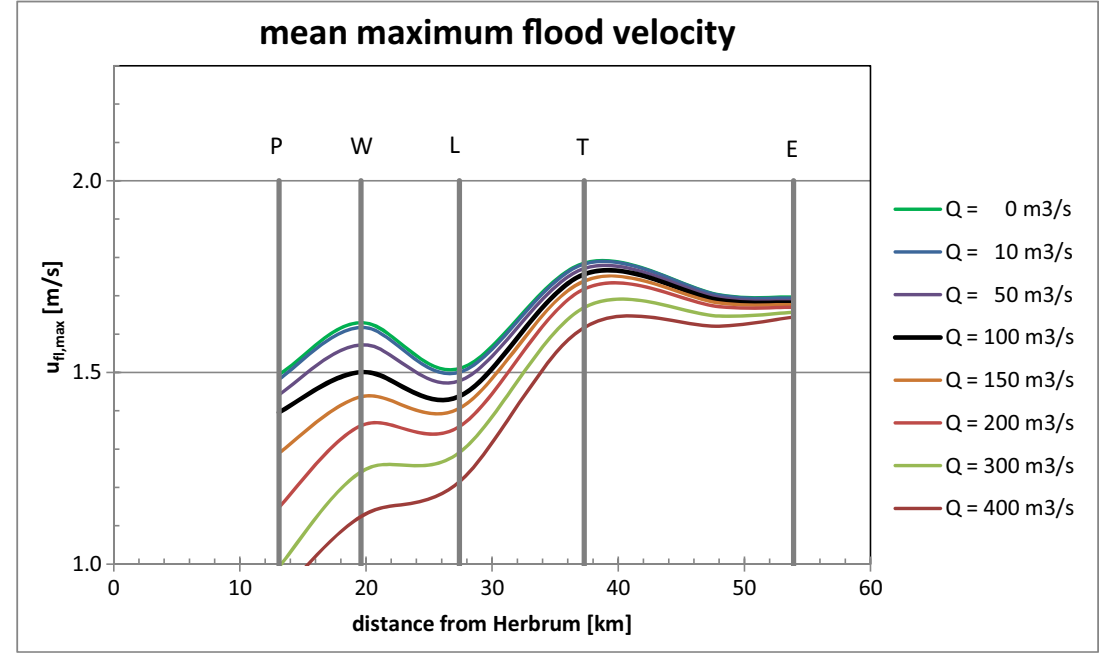

Next, we assess the variation in tidal asymmetry as a function of river discharge from the computed hydrodynamics. We use two different definitions for the tidal asymmetry: one based on the ratio of peak flood and ebb velocities (Eq. (1)) and the second based on the ratio of the flux during flood and during ebb (Eq. (2)), thus accounting for the often shorter length of the flood period when the peak flood velocity exceeds the peak ebb velocity. In the latter, we distinguish between internal asymmetry (Eq. (2a)) and asymmetry in horizontal sediment transport (Eq. (2b)). Internal tidal asymmetry is assumed to scale with the turbulent kinetic energy, i.e. $U^{2}$. This scaling parameter also reflects the denominator of the (bulk) Richardson number, the dominant scaling parameter for stratified flow. The horizontal sediment flux is assumed to scale with the product of the saturation concentration (e.g. Winterwerp 2001) and the flow velocity, i.e. with $U^{4}$. Note that because the simulation time covers 4 weeks, spring-neap effects are implicitly included in this analysis.

asymmetry in peak velocity : $A_{\mathrm{p}}=\frac{\hat{u}_{\text {flood }}}{\hat{u}_{\text {ebb }}}$

asymmetry in vertical mixing : $A_{\mathrm{m}}=\frac{T_{\mathrm{ebb}}}{T_{\mathrm{fl}}} \int_{\text {LWS }}^{\text {HWS }} u^{2} \mathrm{~d} t / \int_{\mathrm{HWS}}^{\text {LWS }} u^{2} \mathrm{~d} t$

asymmetry in horizontal transport : $A_{\mathrm{t}}=\frac{T_{\mathrm{ebb}}}{T_{\mathrm{fl}}} \int_{\mathrm{LWS}}^{\text {HWS }} u^{4} \mathrm{~d} t / \int_{\text {HWS }}^{\text {LWS }} u^{4} \mathrm{~d} t$

where $u(x, t)=Q(x, t) / A(x, t)$, in which $Q$ is the time-varying discharge at location $x$ in the river, as computed with Delft3D, $A$ is the computed river's cross section at that time and place, $\hat{u}$ is the peak velocity, and $T_{\mathrm{ebb}}$ and $T_{\mathrm{fl}}$ are the durations of the ebb and flood period, respectively. The asymmetries along the river as a function of river flow, as assessed from the Delft3D simulations, are presented in Fig. 8. All definitions of the tidal asymmetry reveal that conditions become less flood-dominant or even ebb-dominant with increasing river flow.

The results of Fig. 8 are summarized in Fig. 9, depicting the transition from flood to ebb dominance along the river as a function of river flow. Thus, the river flow affects tidal asymmetry, rather than enhancing the flushing of SPM (for the conditions studied in this paper). The commonly used ratio between peak flood and peak ebb velocity $A_{\mathrm{p}}$ yields a more gentle condition for flood dominance, while the asymmetry in horizontal transport $A_{\mathrm{t}}$ yields the stricter condition, as shown in Fig. 9. The difference, though, is not too large; thus, $A_{\mathrm{p}}$ can be used as a first indication. Yet, our analysis shows that the ratio of peak flood and peak ebb velocity may be misleading in case of varying river discharges. Further, it is important to note that down-estuary of Terborg (T), no ebb-dominant conditions are expected at river flows up to $300 \mathrm{~m}^{3} / \mathrm{s}$ : this part of the river is always flood-dominant. For facilitating the analyses in the following sections, the transitional discharges for four stations are summarized in Table 2.

A logarithmic fit through the computational points for the asymmetry in peak velocity in Fig. 9 yields $y=14.12 \ln x$. An increase in river flow does reduce the peak flood velocity and enhances the peak ebb velocity simultaneously. In other words, relating the fit in Fig. 9 to the convergence length of the Ems River, we need to double the slope of the logarithmic fit. Rewriting into an exponential form, we obtain the following:

$Q_{\text {trans }, A_{\mathrm{p}}} \propto \exp \{x / 28.2\}$

in which $x=$ distance from Herbrum and $Q_{\text {trans }, A_{\mathrm{p}}}=$ river discharge governing the transition from flood to ebb dominance for peak velocities. The $e$-folding length of $28.2 \mathrm{~km}$ is identical to the convergence length $L_{\mathrm{b}}$ of the Lower Ems 

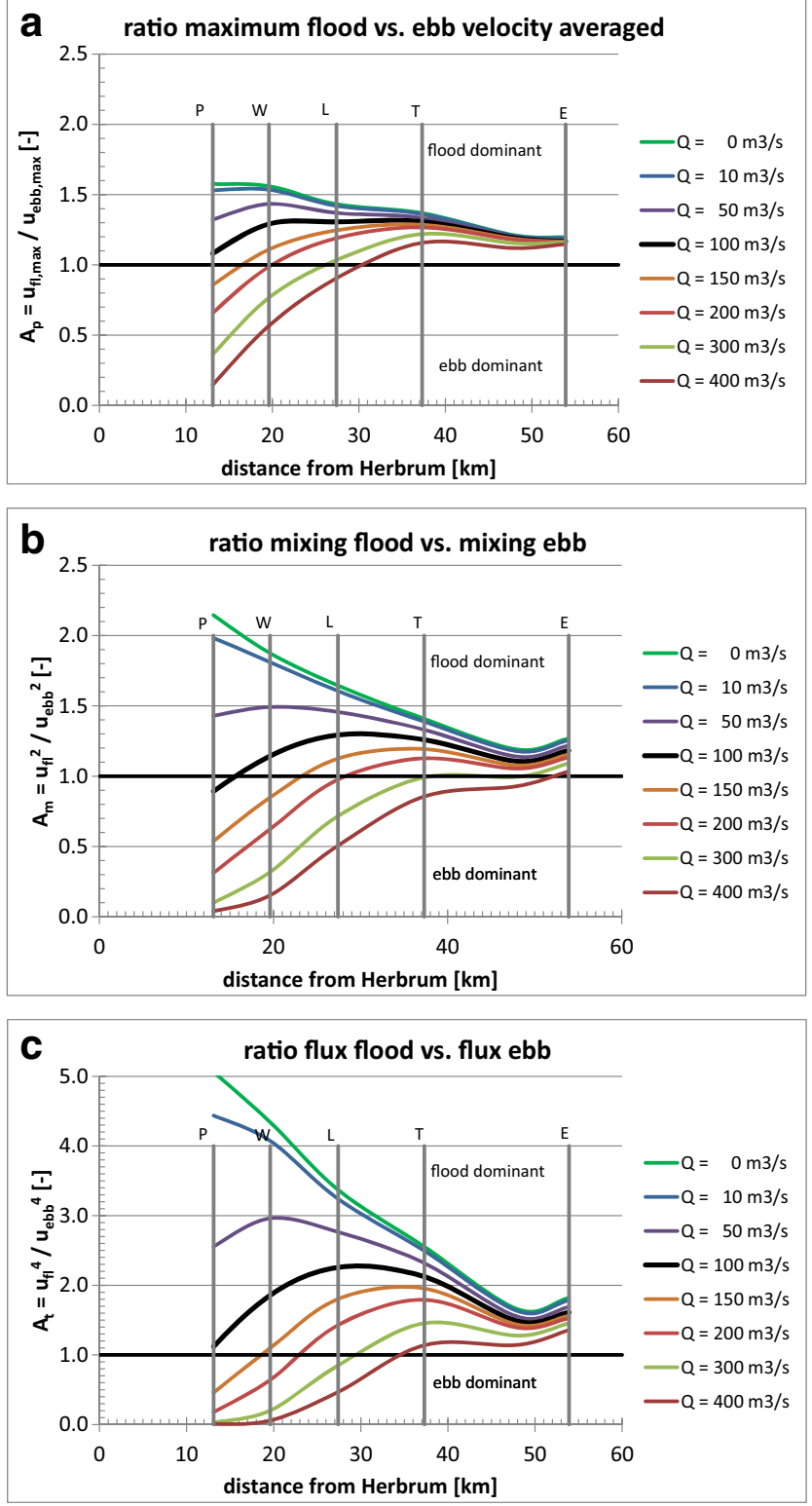

Fig. 8 Asymmetry in peak flow velocity, in vertical mixing and horizontal transport (upper to lower panel), varying along the river and as a function of river flow

River, derived in Winterwerp et al. (2013), varying between 27 and $33 \mathrm{~km}$ along the river.

\section{SPM variations on the semi-diurnal tidal timescale}

In this section, we discuss measured SPM variations over the semi-diurnal tidal cycle. For our analysis and that in Sects. 4 and 5 , we focus on the period of 22 July through 16 September 2010 (see Fig. 10), as the short duration flood event of 27 August is preceded by more than a month of low river flow. We expect that in a month of low river flow, the SPM

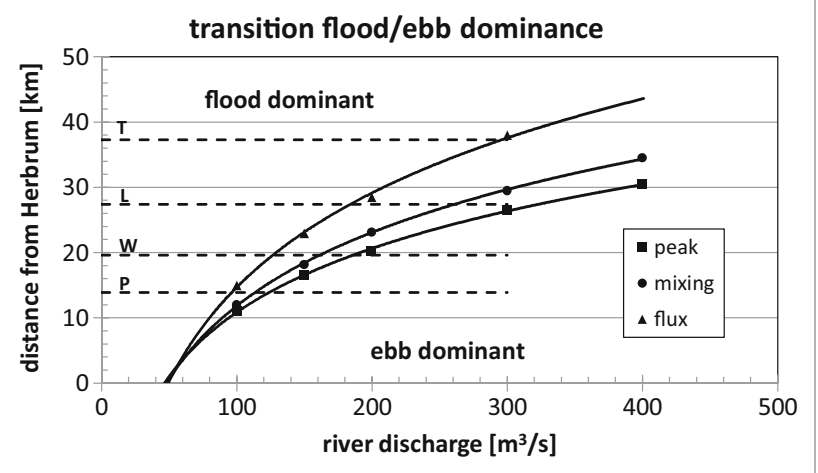

Fig. 9 Transition from flood to ebb dominance along the Ems River as a function of river discharge, depicting asymmetry in peak velocities, internal asymmetry (mixing) and asymmetry in along-river sediment transport (flux)

distribution is then more or less in equilibrium, except for spring-neap variations.

For studying the intra-tidal SPM behaviour, we zoom in on 2 days, i.e. 13-15 August (see Fig. 11). Figure 11 presents the SPM concentrations measured at six stations along the Ems River, in conjunction with the tidal level at Papenburg and Leerort and the river flow measured at Versen. LW at Papenburg is about $1 \mathrm{~h}$ later than at Leerort, whereas HW at Papenburg is about $0.5 \mathrm{~h}$ after HW at Leerort. Hence, we still have a propagating tidal wave, in spite of the simultaneous occurrence of HW and HWS, and LW and LWS, as discussed earlier.

Similar to Figs. 5 and 6, the flood period (rising tide) is much shorter than the ebb period. We observe that directly after local LWS (i.e. LW), SPM values increase rapidly, at Papenburg from about 10 to over $40 \mathrm{~g} / \mathrm{L}$ and at Leerort from about 5 to $15 \mathrm{~g} / \mathrm{L}$. A similar pattern is observed at Weener. Next, towards HWS, when velocities decrease, SPM values decrease again, at Papenburg and Weener to about half the maximum flood value, whereas at Leerort down to almost zero. Then, after the turn of the tide, SPM values at Papenburg and Weener first increase again but then gradually decrease, reaching a minimum of 5-10 g/L at LWS. However, SPM values at Leerort continue increasing during the entire ebb period up to about $10 \mathrm{~g} / \mathrm{L}$.

This picture suggests a pool of fluid/soft mud in the upper reaches of the Lower Ems River, which sits on the bed around LWS, is then mobilized during the onset of flood, partly settles around HWS and is remixed over the vertical during the onset of ebb, while transported down-estuary. Note that the up- and down-estuary transport of high-concentrated mud suspensions was also observed by Talke et al. (2007). Their measurements were carried out during an elongated period of low river flow, hence representative for the analysis of the summer 2010 data in the present paper. Talke's observations on the advection of the fluid mud pool are indicated in the diagram of Fig. 4.

In particular, during ebb tide, SPM records at Weener show strong fluctuations with a period of about $1 \mathrm{~h}$, whence 
Table 2 Computed river discharges at four stations along the Ems River for the transition between flood and ebb dominance, using the three definitions of Eqs. (1 and 2a)

\begin{tabular}{lllll}
\hline & $\mathrm{kmr}$ & $Q_{\text {trans }}$ for $A_{\mathrm{p}}\left(\mathrm{m}^{3} / \mathrm{s}\right)$ & $Q_{\text {trans }}$ for $A_{\mathrm{m}}\left(\mathrm{m}^{3} / \mathrm{s}\right)$ & $Q_{\text {trans }}$ for $A_{\mathrm{t}}\left(\mathrm{m}^{3} / \mathrm{s}\right)$ \\
\hline Papenburg (P) & 13.9 & 125 & 114 & 97 \\
Weener (W) & 19.6 & 191 & 163 & 38 \\
Leerort (L) & 27.4 & 327 & 260 & 184 \\
Terborg (T) & 37.3 & - & - & 300 \\
\hline
\end{tabular}

We have no results for $Q>300 \mathrm{~m}^{3} / \mathrm{s}$ averaging over these fluctuations, the ebb SPM is again about $10 \mathrm{~g} / \mathrm{L}$ lower than the flood SPM. These fluctuations in SPM are also observed during ebb at Papenburg and Leerort, but less intense. We postulate that these fluctuations are induced by internal waves on the mud-water interface. At the interface of such two-layer systems, internal waves are generated, known as Kelvin-Helmholtz instabilities or Holmboe waves (Winterwerp et al. 1992). Such progressive internal waves have been explicitly measured on the fluid mud-water interface just down-estuary of Leerort with acoustic methods. Figure 12 shows that these waves have a length of about $10 \mathrm{~m}$ and a height of about $1 \mathrm{~m}$. The internal wave dimensions vary with water depth and flow velocity. They were systematically observed, mainly during ebb and to a lesser extent during flood, hence consistent with our SPM observations. Note that at times, internal waves have been observed penetrating up to the water surface. We postulate that the more pronounced observations of internal waves during ebb are to be attributed to the rapid mixing during flood, breaking down vertical stratification.
We can estimate the period of the internal waves in Fig. 12 from their celerity $c_{i}=\sqrt{\Delta \rho_{f m} g \delta / \rho}$, assuming non-viscous conditions (e.g. Gade 1958; Kranenburg et al. 2011). For a variety of fluid mud thicknesses $\delta$ and excess density $\Delta \rho_{f m}$, Fig. 13 shows that $c_{i}$ is expected to vary between 0.5 and $1.7 \mathrm{~m} / \mathrm{s}$, though likely in the range of $1-1.3 \mathrm{~m} / \mathrm{s}$. Hence, we estimate the period of these internal waves somewhere between 10 and $180 \mathrm{~s}$, though most likely values are below 20 s (see also Fig. 13; Schrottke \& Bartholomä 2008; Held, et al. 2013).

These periods are much shorter than the period of the SPM fluctuations in Fig. 11. The latter have been monitored at a frequency of $5 \mathrm{~min}$. Thus, aliasing is expected in the measured SPM signal. This argument is further supported by the height of the internal waves of about $1 \mathrm{~m}$, which would generate substantial variations in SPM readings. Thus, we are confident that the SPM fluctuations in Fig. 11 indeed originate from internal waves.

Our observations also suggest that the amount of SPM in the water column is largely governed by the high velocities at

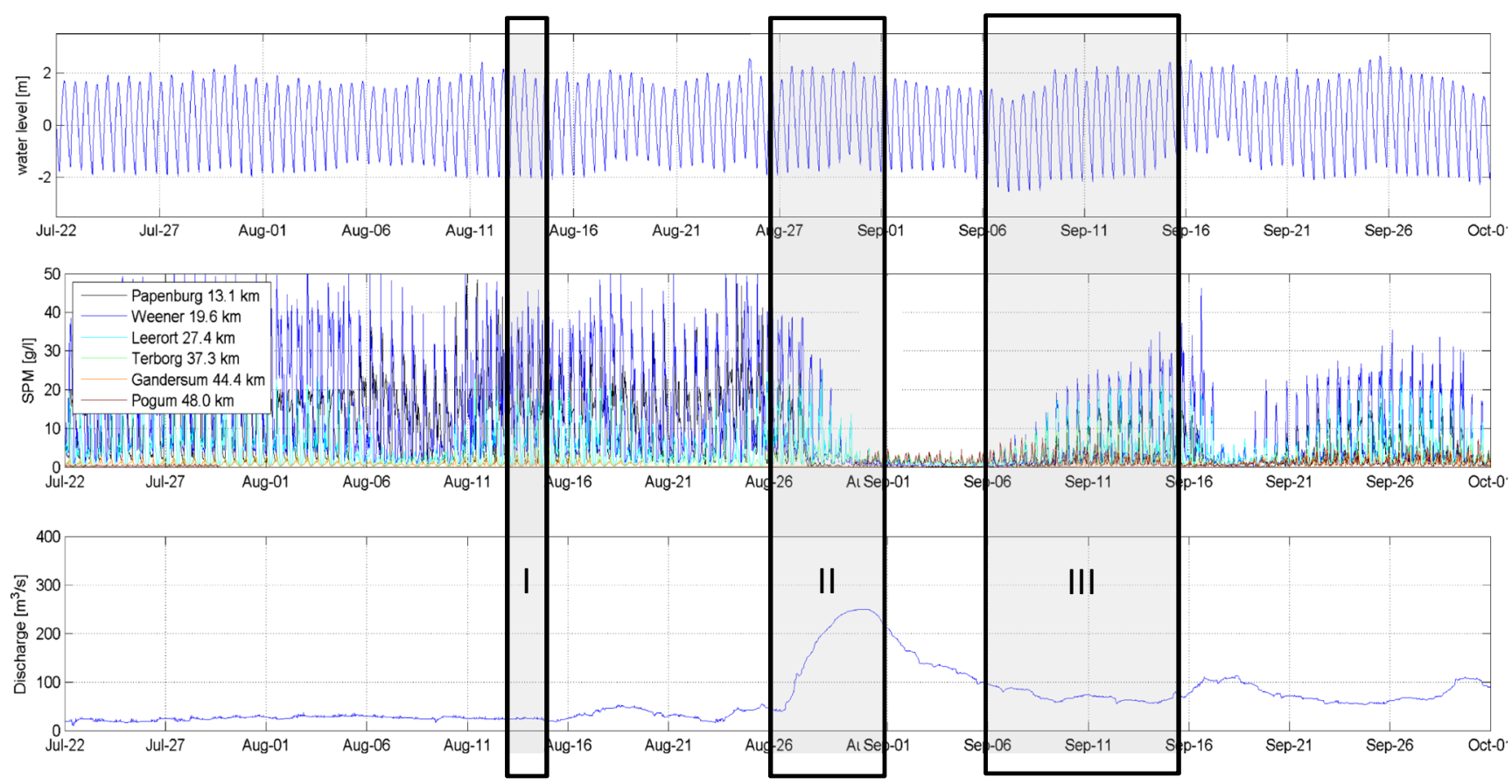

Fig. 10 Time series of tidal range at Papenburg, SPM at six stations in the Ems River and river discharge in summer 2010 with phase I: elongated period of low river flow, phase II: increasing river flow and phase III: relaxation to mean flow discharge. Note the variation in tidal range at Papenburg 


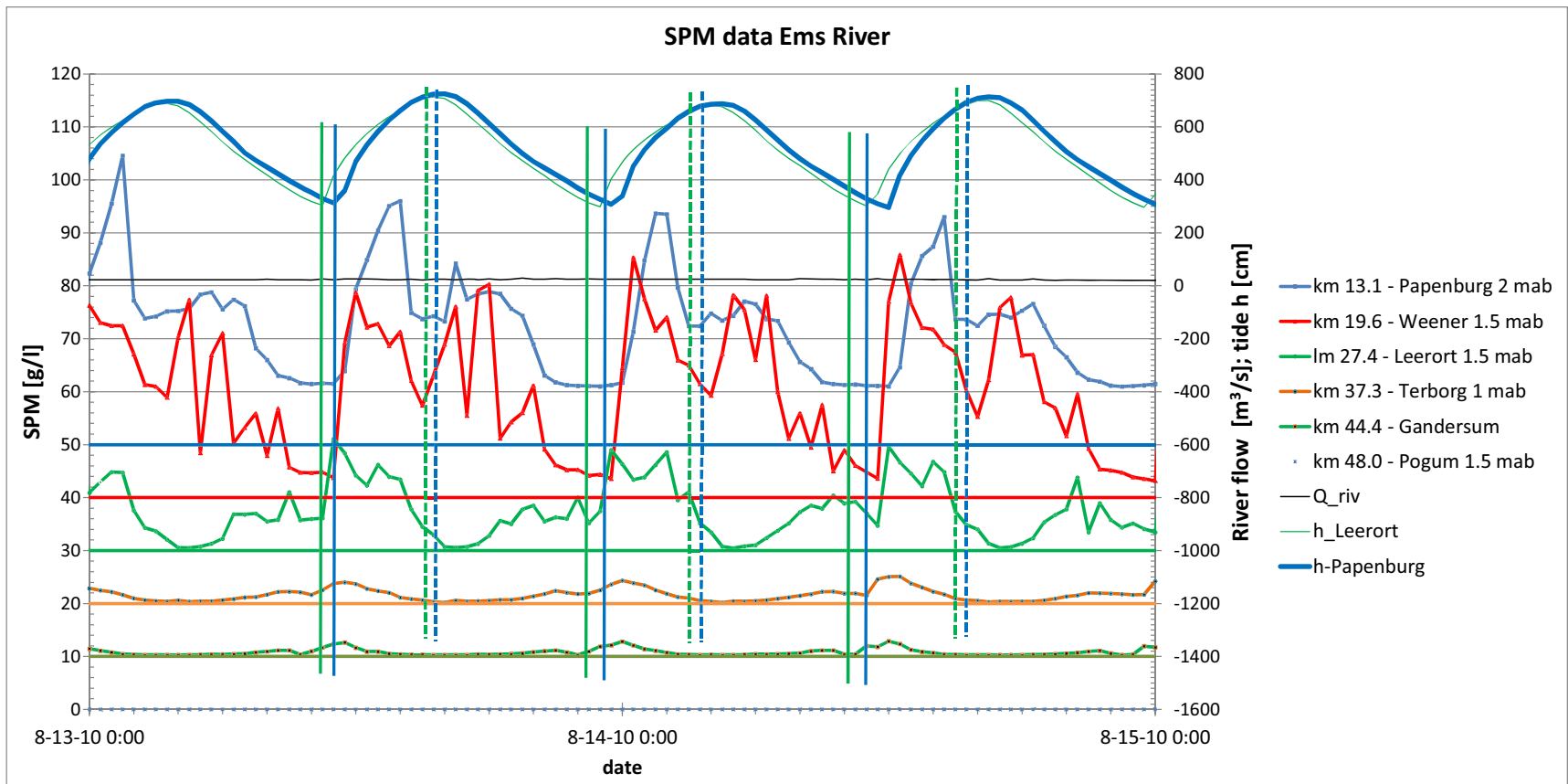

Fig. 11 SPM values measured at six stations along the Lower Ems River during phase I, i.e. low river discharge $\left(25 \mathrm{~m}^{3} / \mathrm{s}\right)$. The lower six lines represent the measured SPM at the five stations in the legend-note that the SPM basis for each station is shifted by $10 \mathrm{~g} / \mathrm{L}$ for clarity of the graph. The (horizontal) black line depicts the constant river flow, and the

the onset of flood, eroding (entraining) and mixing large amounts of sediment over the water column. Around HWS, the sediment settles slowly. If we assume a settling velocity of $0.5 \mathrm{~mm} / \mathrm{s}$, it would take almost $3 \mathrm{~h}$ to cleanse the entire water column of $5 \mathrm{~m}$. Hence, with increasing ebb velocities, sediments which did not settle completely are being remixed over the water column. However, during ebb, velocities are too low to mix the sediment again to same height as during flood - the flow's kinetic energy is too small to overcome the required potential energy (e.g. Winterwerp 2001). Yet, during ebb, hyper-turbid water is advected down-estuary (see also Talke et al. 2007) explaining the ongoing increase in SPM at Leerort during ebb, while SPM readings at Papenburg and Weener decrease. Winterwerp (2011) also suggested that floc sizes during ebb are much larger than during flood, which would explain why the sediment settles faster towards LWS than towards HWS.

The strong asymmetry in measured SPM values with computed flow velocity is further depicted in Fig. 14, showing two upper lines depict the tide at Leerort (solid green) and Papenburg (solid blue). Vertical lines are added to illustrate the timing of LWS (HWS) and the response of SPM for the stations Leerort (green lines) and Papenburg (blue lines)

much higher SPM values during flood. During accelerating tide, SPM values rise rapidly in response to increasing mixing rates, whereas during decelerating tide, a more gradual response is observed.

Note that though the SPM concentrations are high, the suspension still behaves fully Newtonian at the measured concentrations of $40 \mathrm{~g} / \mathrm{L}$ (Winterwerp and Van Kesteren 2004). However, as the larger vertical velocity gradients occur close to the bed, the lower layer becomes the more turbulent (Le Hir 1997). Hence, mixing of the stratified water-sediment mixture after LWS is governed by entrainment of water from the upper part of the water column into the accelerating water-sediment mixture, as described in Bruens et al. (2012). This kind of entrainment induces an initial rising of the water-sediment interface. Indeed, such entrainment is documented by Schrottke \& Bartholomä (2008) (see Fig. 15) and Held et al. (2013). When, for example, the ebb flow accelerates, the water-fluid mud interface rises indeed, becoming more and more

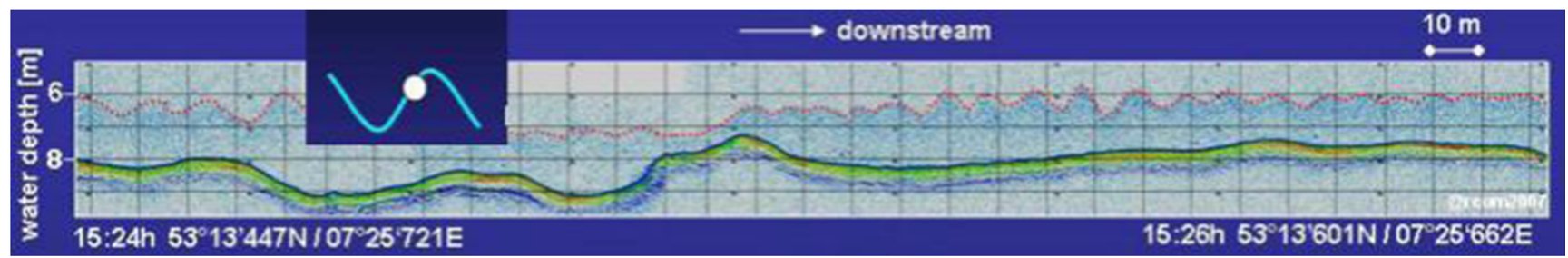

Fig. 12 Internal waves measured along the river just down-estuary of Leer in 2007 on 21 September 2005 during the last phase of the ebb tide. The river flow has been low for many weeks. The length of these waves is about $10 \mathrm{~m}$ 
Fig. 13 Estimated celerity of the internal wave on the fluid mudwater interface during flood as a function of fluid mud density and thickness

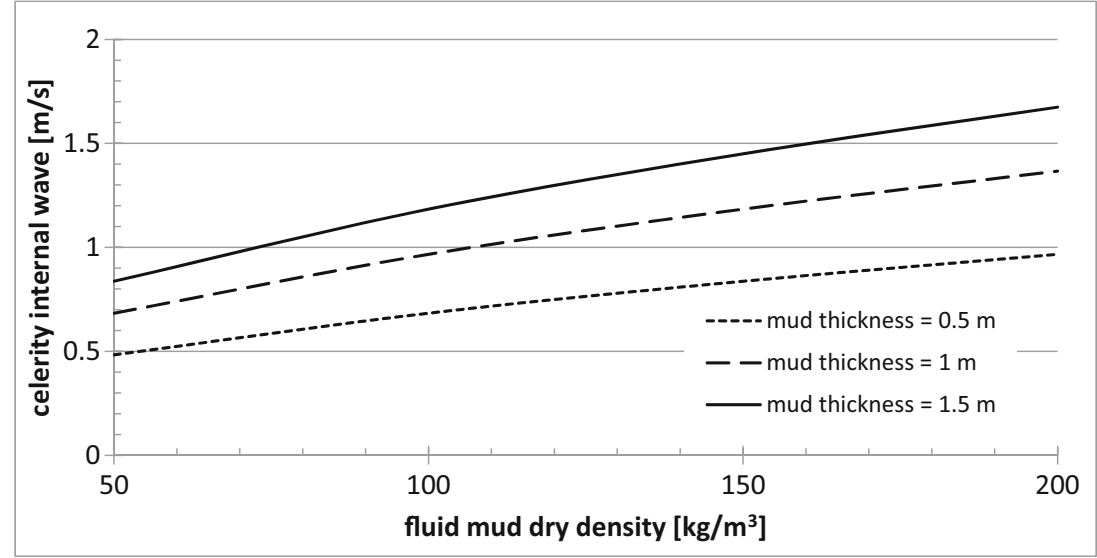

blurred around maximum ebb velocity. While accelerating, the velocity of/within the fluid mud layer can increase up to $1.45 \mathrm{~m} / \mathrm{s}$ (see Held et al. 2013).

\section{SPM variations on the spring-neap tidal timescale}

The tide in the Ems River is subject to a profound spring-neap cycle (see Fig. 16). Table 3 summarizes the computed tidal ranges $2 a$ and velocities $U$ at neap and spring tide at the four stations of Table 2, showing an increase/decrease of about $20 \%$ in tidal range and velocity at spring and neap tide, respectively. Up-estuary of Terborg, the tidal range is almost constant along the river, which is another indication for synchronicity

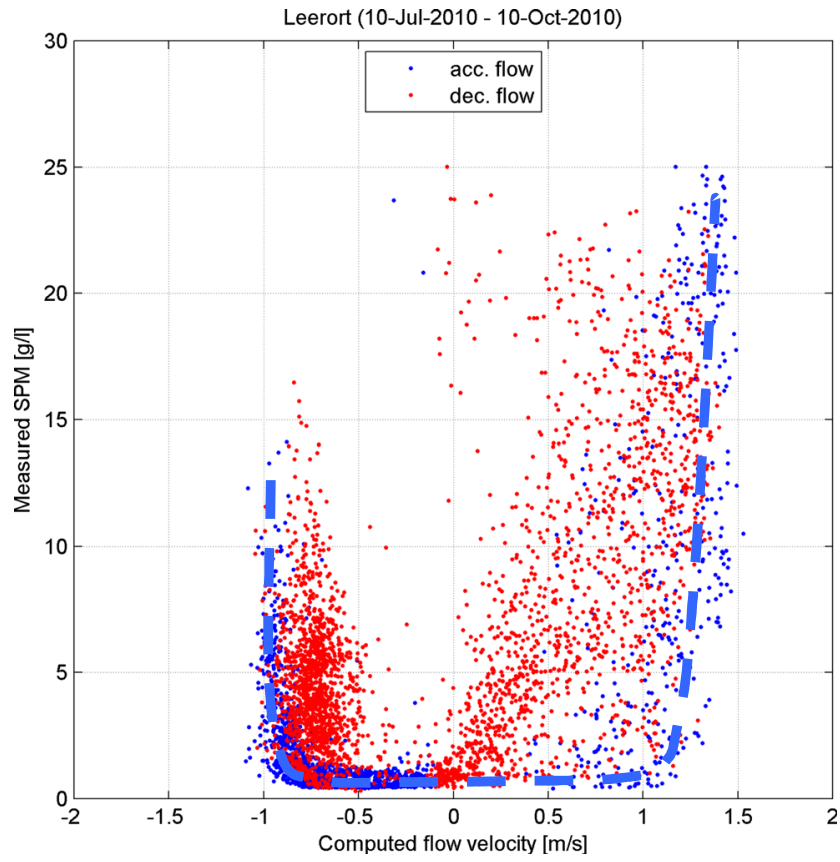

Fig. 14 Correlation between measured SPM values with computed flow velocity at Leerort (flood velocities are positive); data points at every 10 min for the period 10 July through 10 October 2010. The dashed blue line represents a visual fit through the data during accelerating tide
(Friedrichs 2010; Winterwerp and Wang 2013). Flow velocities, of course, decrease towards the head of the tidal river, i.e. Herbrum. Yet, the spring-neap effect remains constant along the river. Figure 17 thus shows that the computed tidal flow amplitude scales more or less linearly with the computed tidal range. Therefore, we can use the tidal range as a proxy for analysing the spring-neap effects on SPM.

As vertical mixing, as well as entrainment scale with the velocity squared, we expect a substantial effect of the springneap cycle on the SPM values. For analysing this spring-neap

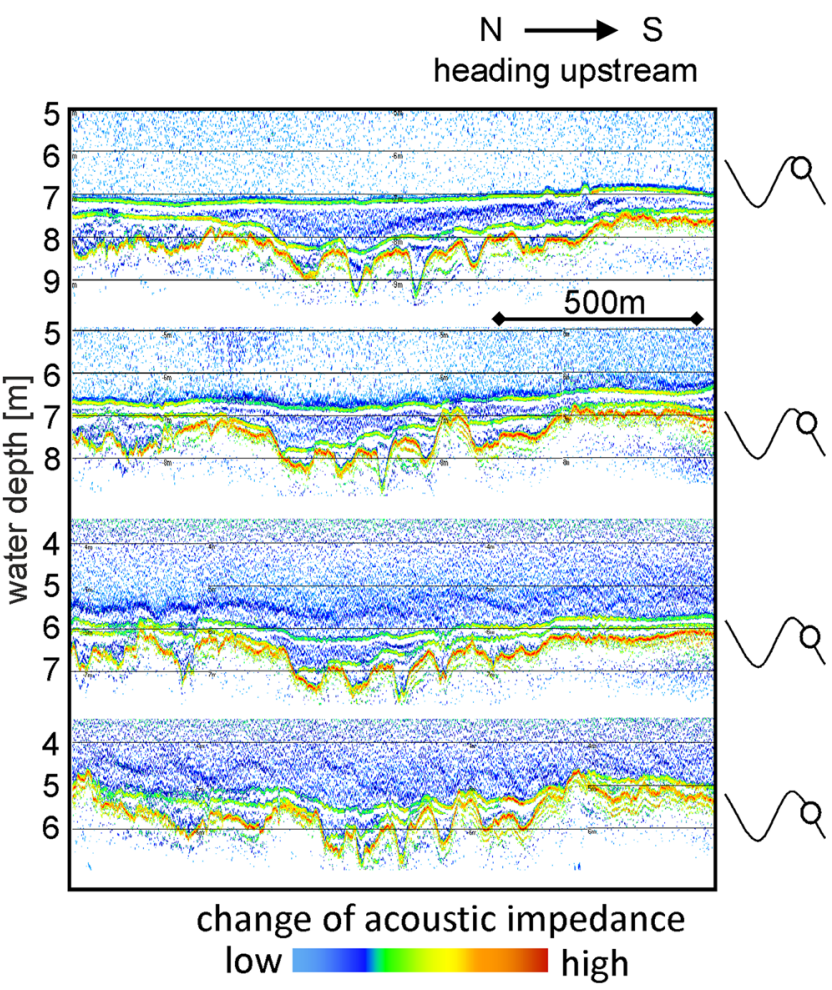

Fig. 15 Acoustic images of sediment structure in the Lower Ems River, measured on 20 September 2006 between 33.7 and $35.7 \mathrm{~km}$ (just upestuary of Terborg, Fig. 4), using a multi-frequency echo sounder. At HW, i.e. HWS, the water sediment distribution is highly stratified, whereas during accelerating ebb tide, the water-sediment interface rises and is then mixed 

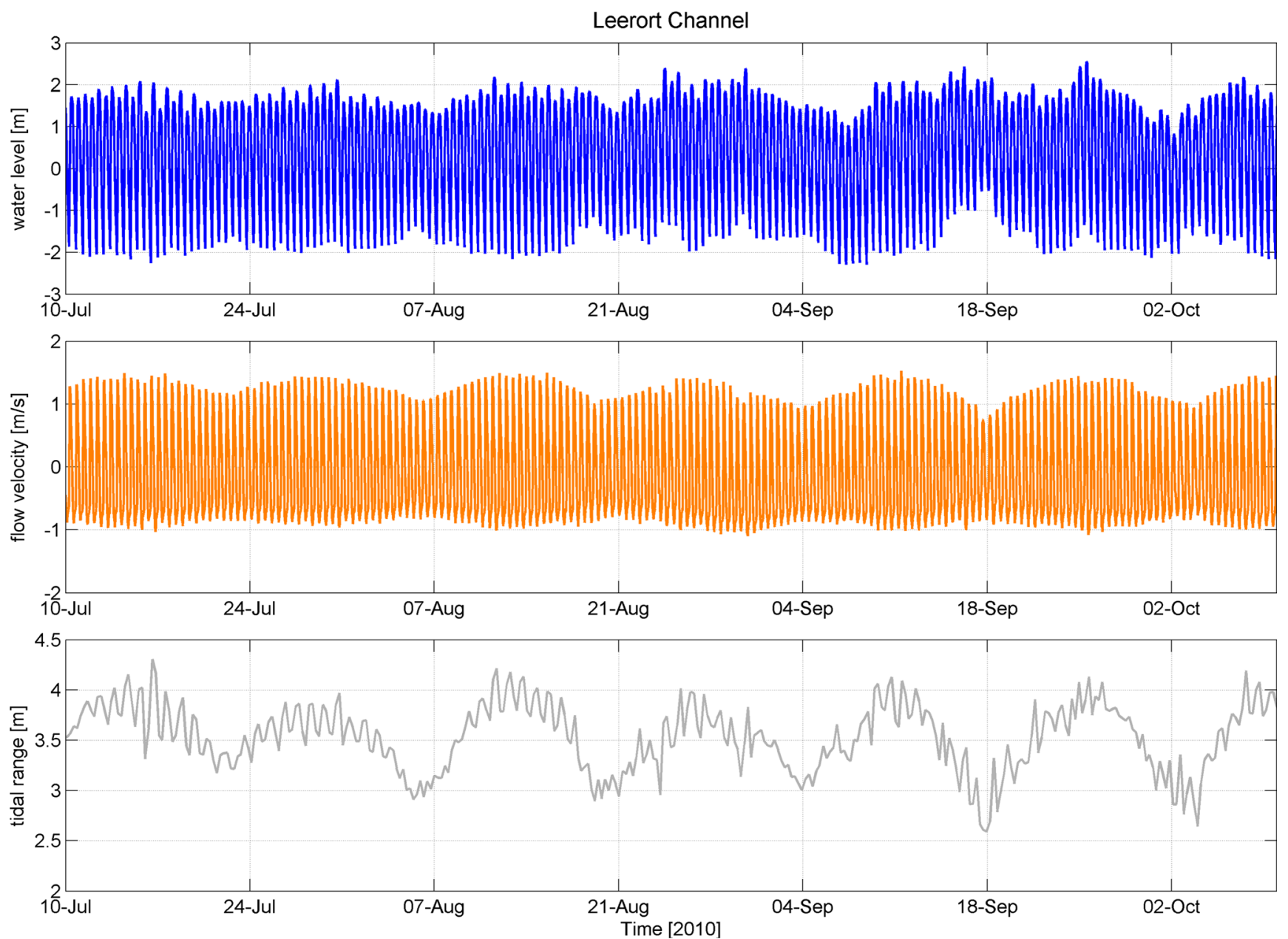

Fig. 16 Computed flow velocity and tidal range at Leerort showing a profound spring-neap cycle in water level and tidal flow velocity

effect, we compare measured SPM values with the computed flow velocity at Leerort for the period 22 July through 22 August 2010, hence including two full spring-neap cycles. The river flow in this period is almost constant and low $\left(25 \mathrm{~m}^{3} / \mathrm{s}\right)$. The time series in Fig. 18 indeed show a strong response of the SPM concentrations to the spring-neap variation, with a strong reduction in SPM during neap tide. Note that again, SPM values during flood are always much larger than during ebb, thus suggesting that it is the peak flood velocity which governs the amount of fines in the water column.

Table 3 Computed spring-neap variation in amplitudes of tidal level and flow velocity

\begin{tabular}{llllll}
\hline & \multicolumn{3}{l}{ Neap tide } & \multicolumn{3}{l}{ Spring tide } \\
\hline & $\mathrm{kmr}$ & $2 a(\mathrm{~m})$ & $U(\mathrm{~m} / \mathrm{s})$ & $2 a(\mathrm{~m})$ & $U(\mathrm{~m} / \mathrm{s})$ \\
Papenburg & 13.1 & 3.1 & 0.9 & 3.8 & 1.1 \\
Weener & 19.6 & 3.1 & 1.0 & 3.8 & 1.2 \\
Leerort & 27.4 & 3.1 & 1.0 & 3.9 & 1.2 \\
Terborg & 37.3 & 3.1 & 1.2 & 3.9 & 1.4 \\
\hline
\end{tabular}

\section{Effect of short-term variations in river flow}

Next, we analyse the period of increasing river discharge, while the tide evolves towards neap conditions, e.g. the period between 26 August and 1 September 2010 (see Figs. 10, 19 and 20). In about 3 days, the river flow increases from 25 to almost $250 \mathrm{~m}^{3} / \mathrm{s}$ and the tidal range decreases from about $3.8 \mathrm{~m}$ to $3.3 \mathrm{~m}$ (depending on the station). Figure 20 depicts that with increasing river flow, the SPM profile first collapses at Papenburg, then at Weener and last at Leerort, though at Leerort, SPM values do not completely reduce to zero.

It is important to note that until collapse, the pattern of Fig. 11 continues, i.e. a rapid increase in SPM directly after LWS. A second important observation is that SPM values down-estuary do not increase when SPM values at more upestuary located stations decrease, as one would expect in the case of down-estuary advection (flushing) by the river flow.

From Fig. 20, we deduce that the river discharges at which the SPM profile collapses are $150 \mathrm{~m}^{3} / \mathrm{s}$ (Papenburg), $240 \mathrm{~m}^{3} / \mathrm{s}$ (Weener) and $250 \mathrm{~m}^{3} / \mathrm{s}$ (Leerort). These river discharges depict no correlation with the transitional discharges at which 

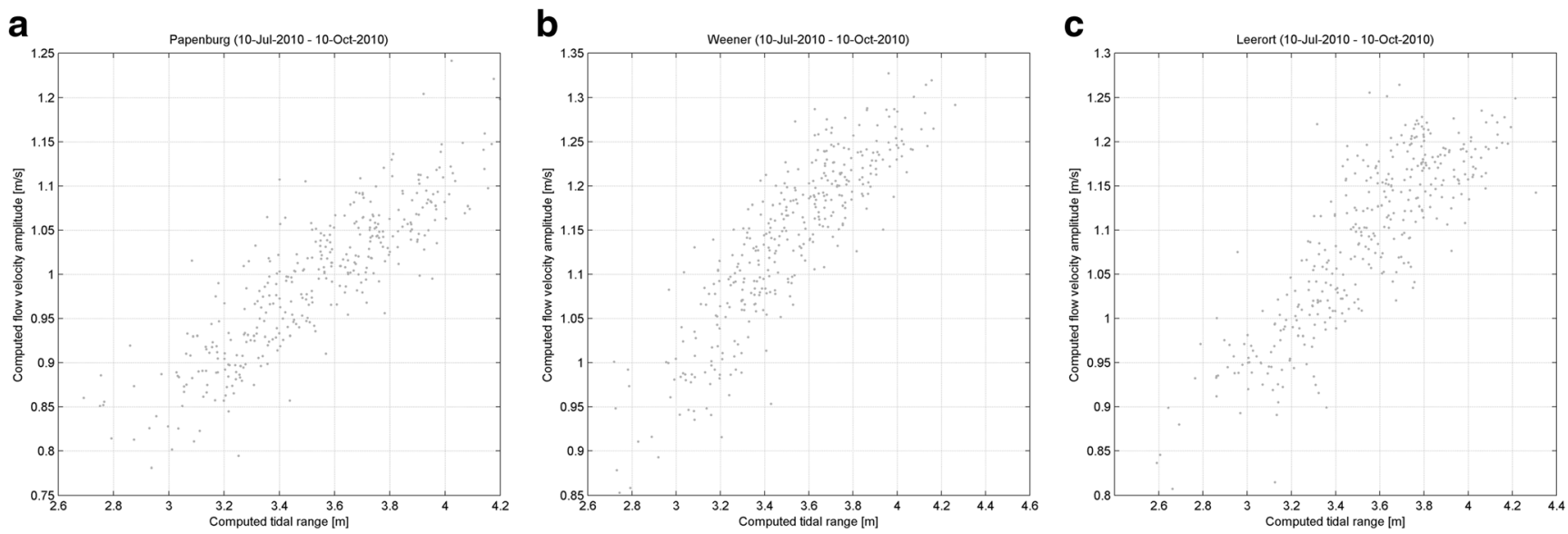

Fig. 17 Relation between computed amplitude of tidal range and velocity for the stations Papenburg, Weener and Leerort, showing a fairly linear relation between tidal range and maximum flow velocity

flood dominance changes to ebb dominance, as depicted in Fig. 9 and Table 2. Hence, the response of SPM values to short changes in river discharges cannot be attributed to one of the tidal asymmetries defined in Fig. 9.
However, the response of SPM to the peak flood velocities reveals a different story. From Figs. 19 and 20, we read that SPM profiles at Papenburg and Leerort collapse when the cross-sectional averaged peak flood velocity decreases below
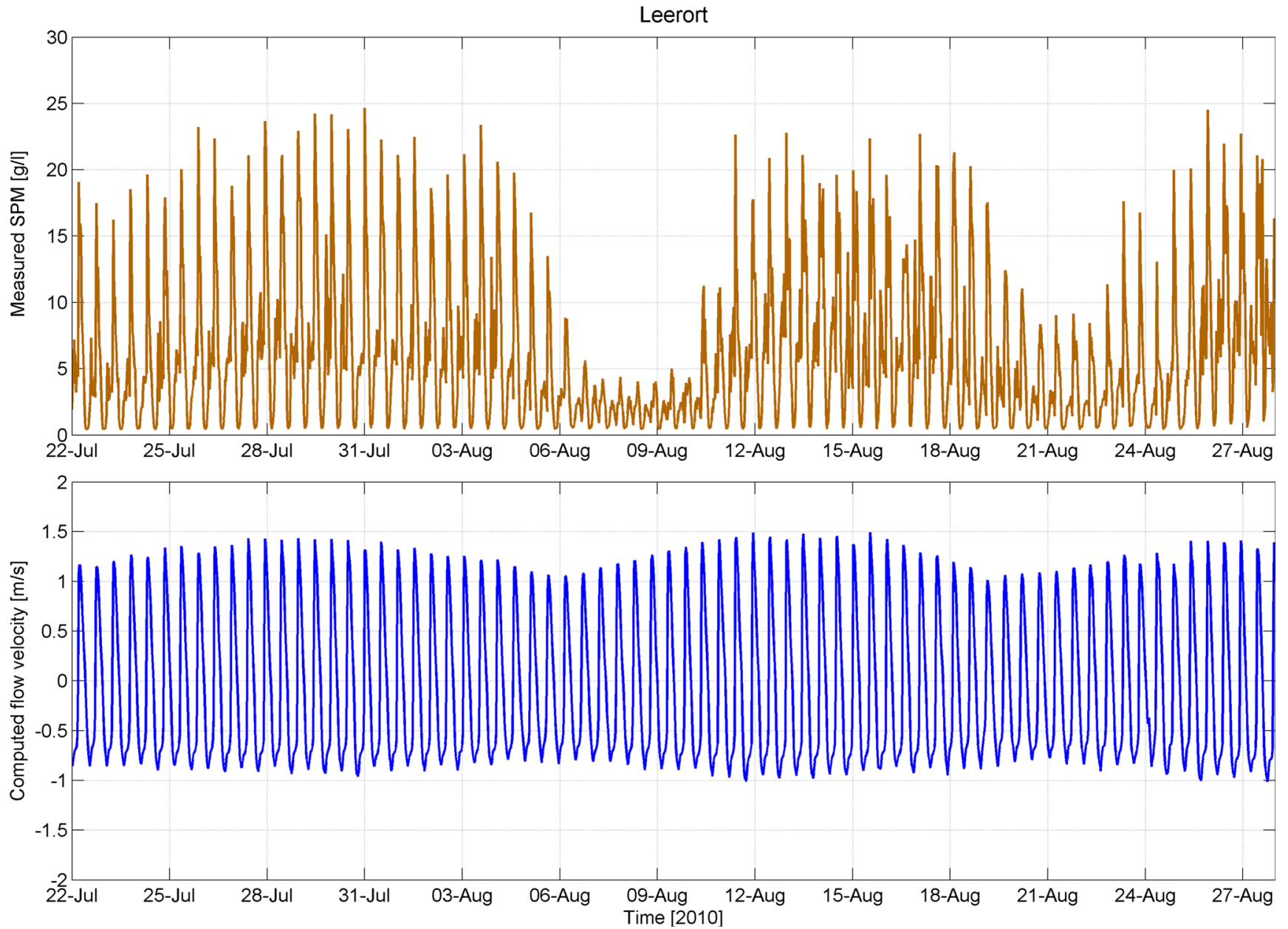

Fig. 18 Variations in measured SPM and computed tidal velocity at Leerort, 22 July through 27 August, at low and almost constant river flow, covering two spring-neap cycles 


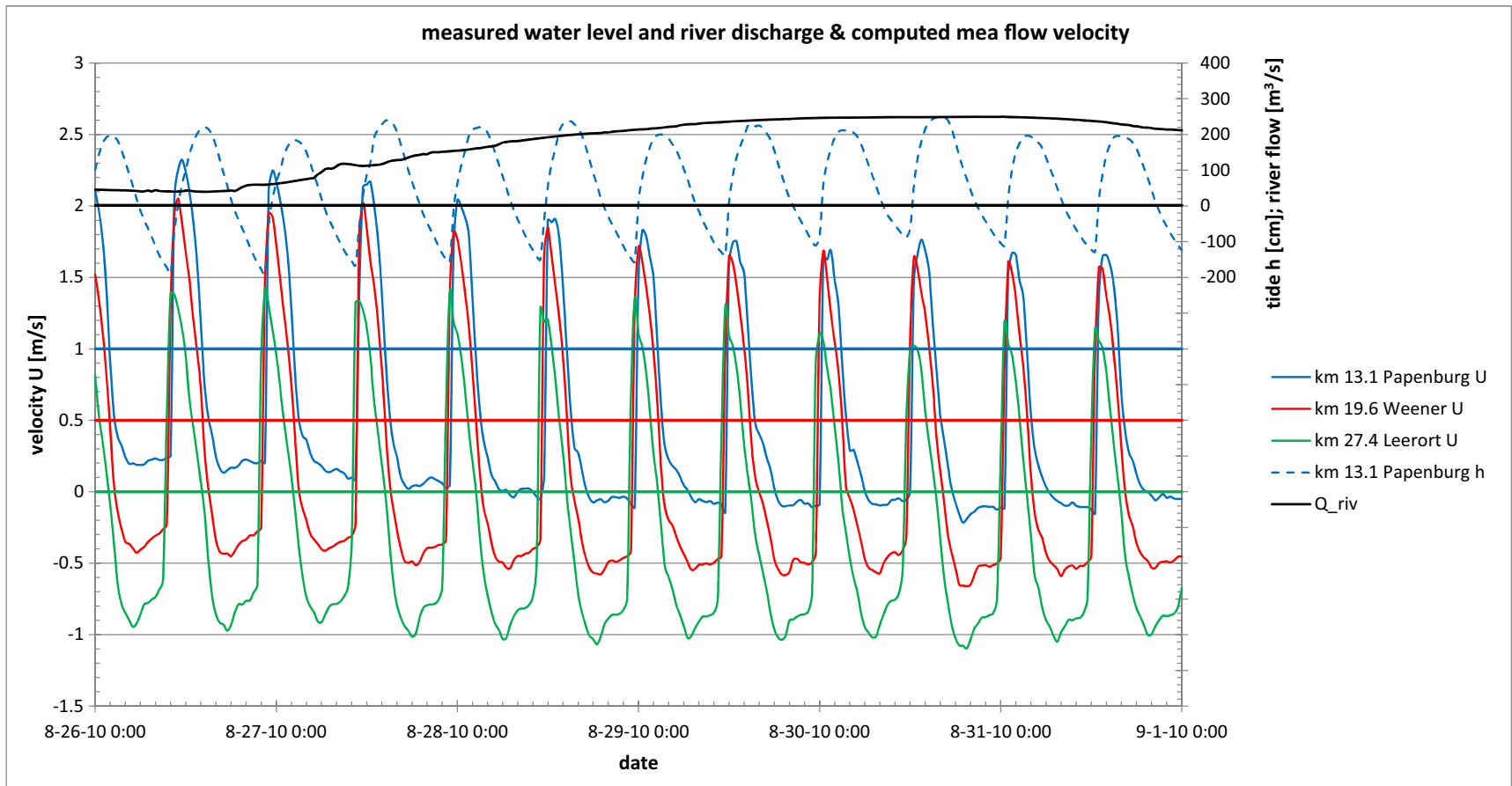

Fig. 19 Water level at Papenburg (upper dashed blue line), discharge at Versen (solid black line) and computed cross-sectional mean flow green) for phase II, i.e. increasing river discharge $\left(40-250 \mathrm{~m}^{3} / \mathrm{s}\right)$ - note velocity at Papenburg (solid blue), Weener (solid red) and Leerort (solid that vertical velocity axes are shifted

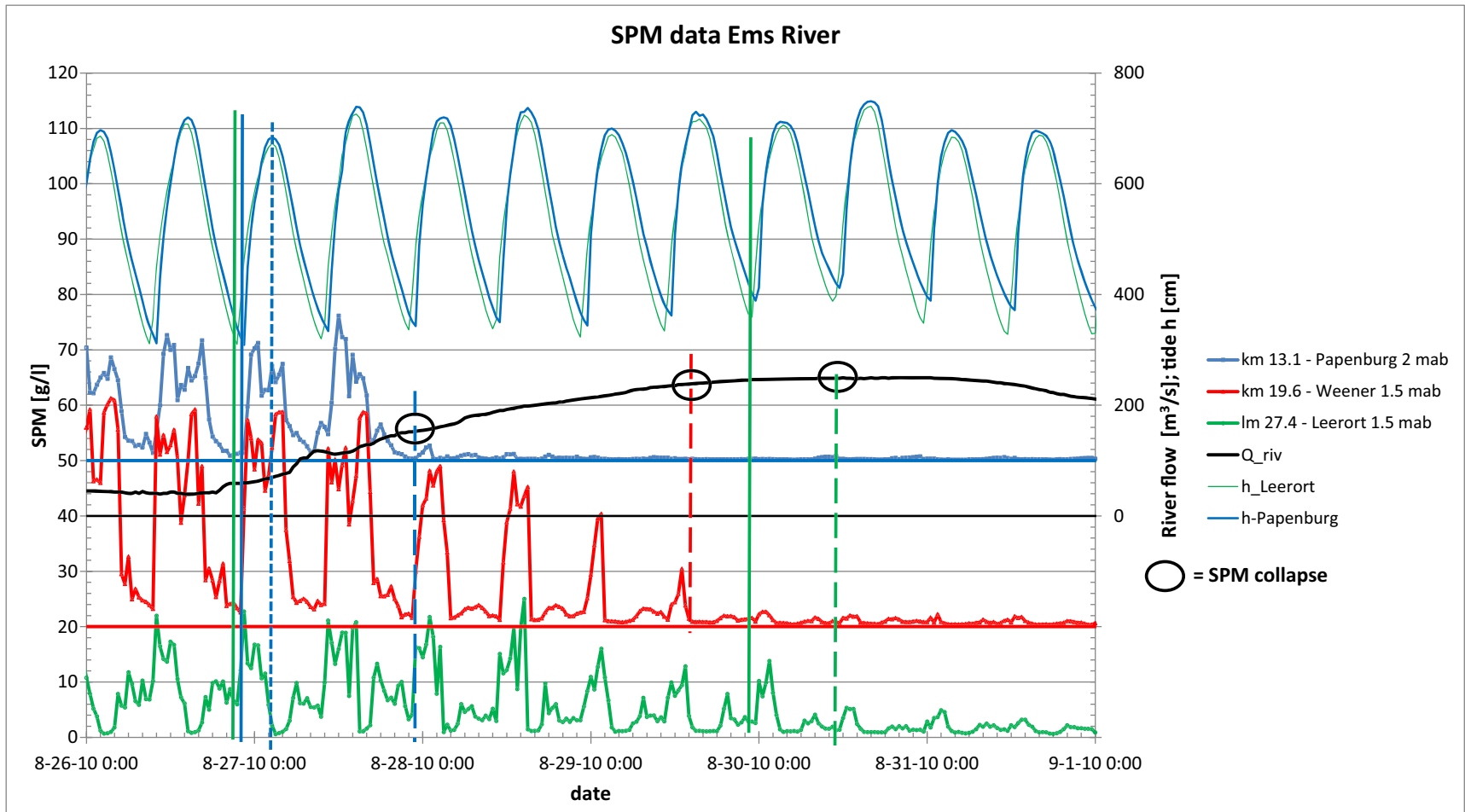

Fig. 20 SPM values at the upper three stations along Ems River (lower three line) for phase II, i.e. increasing river discharge $\left(40-250 \mathrm{~m}^{3} / \mathrm{s}\right)$ note that the SPM basis for each station is shifted by $10 \mathrm{~g} / \mathrm{L}$ for clarity of the graph. The black line depicts the increasing river flow, and the two upper lines depict the tide at Leerort (solid green) and Papenburg (solid blue). Vertical lines are added to illustrate the timing of LWS (HWS) and the response of SPM and the river flow at which SPM collapses (black circles on black curve) for the stations Leerort (dashed green), Weener (dashed red) and Papenburg (dashed blue) 
a critical velocity $U_{\text {cr,c }}$ of $1-1.1 \mathrm{~m} / \mathrm{s}$, whereas at Weener, this occurs around $1.1-1.2 \mathrm{~m} / \mathrm{s}$.

In Sect. 3, we discussed that at low river flow at the onset of flood, flow velocities increase rapidly, up to values of well over $1 \mathrm{~m} / \mathrm{s}$ and that SPM values then increase rapidly. When the peak flood velocity does no longer exceed the critical value $U_{\mathrm{cr}, \mathrm{c}}$, the SPM profiles seem to collapse, or more accurately, the fluid mud sediments are no longer mixed up to the OBS sensors. Figure 13 suggests that the celerity of the internal wave on the mud interface is somewhere between 1 and $1.3 \mathrm{~m} / \mathrm{s}$ (see also Held et al. 2013). This would mean that the internal flow dynamics can become supercritical at higher tidal velocities. At such supercritical conditions, mixing can be intense as the (bulk) Richardson number becomes small, bearing in mind that the (bulk) Richardson number scales with the inverse of the internal Froude number. Hence, an increase in Froude number implies destabilization of the stratified flow. Therefore, we postulate that the rapid mixing after LWS is related to the onset of supercritical flow conditions. At higher river flows, the flood velocities remain subcritical, and mixing is less intense, up to the point where the kinetic energy of the flow is unable to overcome the large stratification in the water column, e.g. at large Richardson numbers.

The data suggest variations in $U_{\mathrm{cr}, \mathrm{c}}$. We believe that these variations have to be attributed to the following:

1. The accuracy of the computed flow velocities

2. The height of the SPM measurements - the exact bed level is difficult to define
3. The accuracy of OBS sensors reduces at large flow velocities and high SPM concentrations

4. The local thickness and density of the fluid mud layer

5. In our analysis, we use cross-sectional averaged velocities while vertical mixing is merely governed by local flow conditions, i.e. the vertical velocity structure which is not properly resolved by the model.

Winterwerp (2001) defined a saturation concentration $C_{\mathrm{s}}$ as an indicator for the maximum amount of fine sediment that can be carried by a turbulent flow, while a relation for $C_{\mathrm{s}}$ was obtained from numerical experiments with a 1DV model:

$C_{\mathrm{s}}=K_{\mathrm{s}} \frac{\rho}{g\left(\rho_{\mathrm{s}}-\rho_{\mathrm{s}}\right) / \rho_{\mathrm{s}}} \frac{u_{*}^{3}}{h W_{\mathrm{s}}} \approx 0.023 \frac{U^{3}}{h W_{\mathrm{s}}}$

in which $u_{*}=$ shear velocity, $h=$ water depth, $W_{\mathrm{s}}=$ settling velocity and $U=$ characteristic velocity. If we substitute $U=U_{\mathrm{cr}, \mathrm{c}}=1.1 \mathrm{~m} / \mathrm{s}, h=5 \mathrm{~m}$ and $W_{\mathrm{s}}=0.5 \mathrm{~mm} / \mathrm{s}(\mathrm{a}$ characteristic settling velocity for fine sediment in the Ems River, see also Winterwerp 2001 and 2006), we obtain $C_{\mathrm{s}} \approx 10 \mathrm{~g} / \mathrm{L}$, which is of the order of the observed values and supports our analysis that the peak flood velocity governs the amount of fine sediments in the water column.

Next, in Figs. 21 and 22, we analyse the recovery of SPM behaviour when the river flow decreases to mean values again. Arbitrarily, we define recovery when SPM values have reached $10 \mathrm{~g} / \mathrm{L}$ again (Fig. 22). Thus, recovery at Leerort and Weener

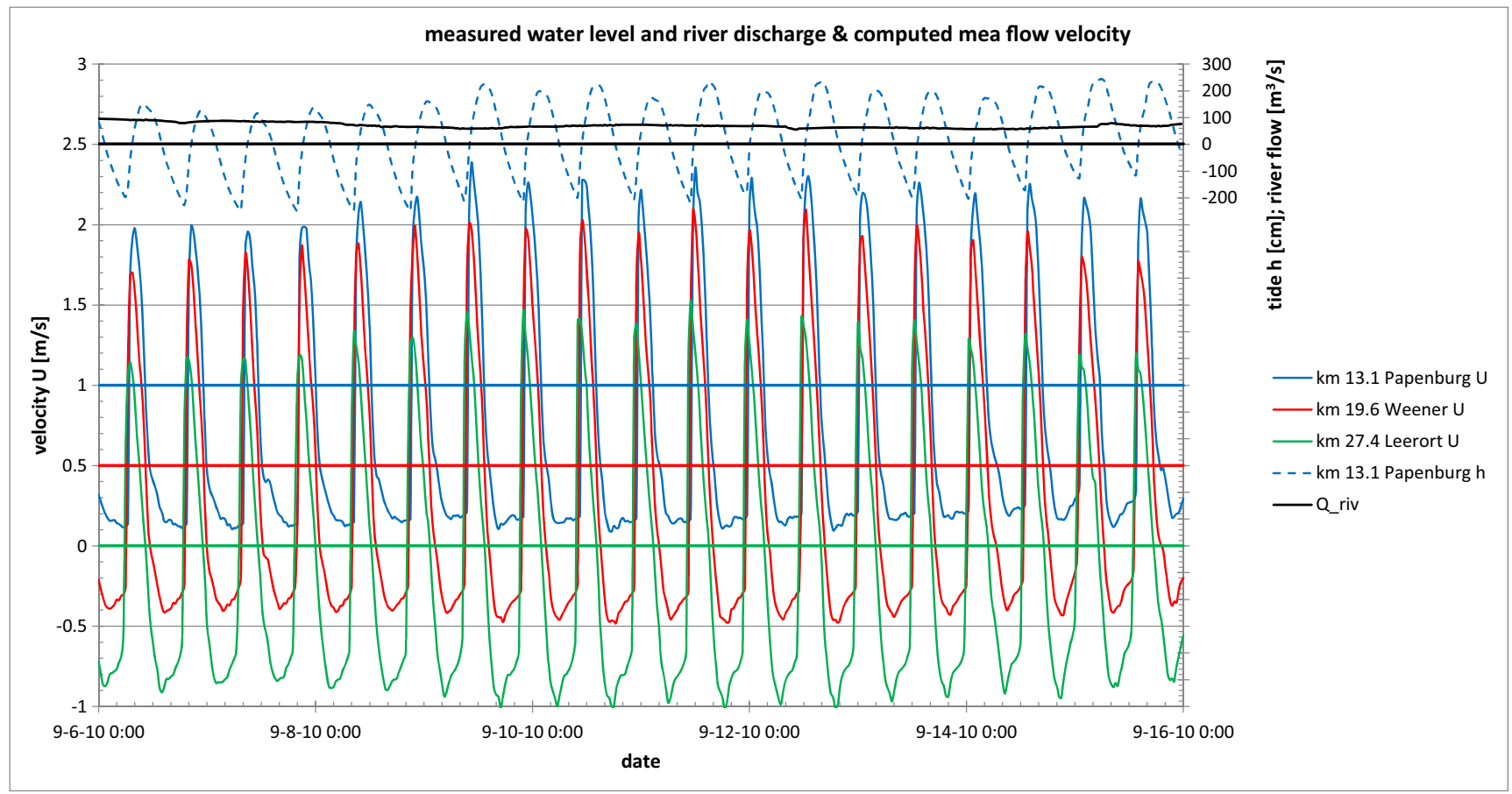

Fig. 21 Water level at Papenburg (dashed blue), discharge at Verssen (solid black) and computed cross-sectional mean flow velocity at Papenburg (solid blue), Weener (solid red) and Leerort (solid green) for phase III, i.e. recovered river discharge $\left(70 \mathrm{~m}^{3} / \mathrm{s}\right)$ - note different axes velocity curves 


\section{SPM data Ems River}

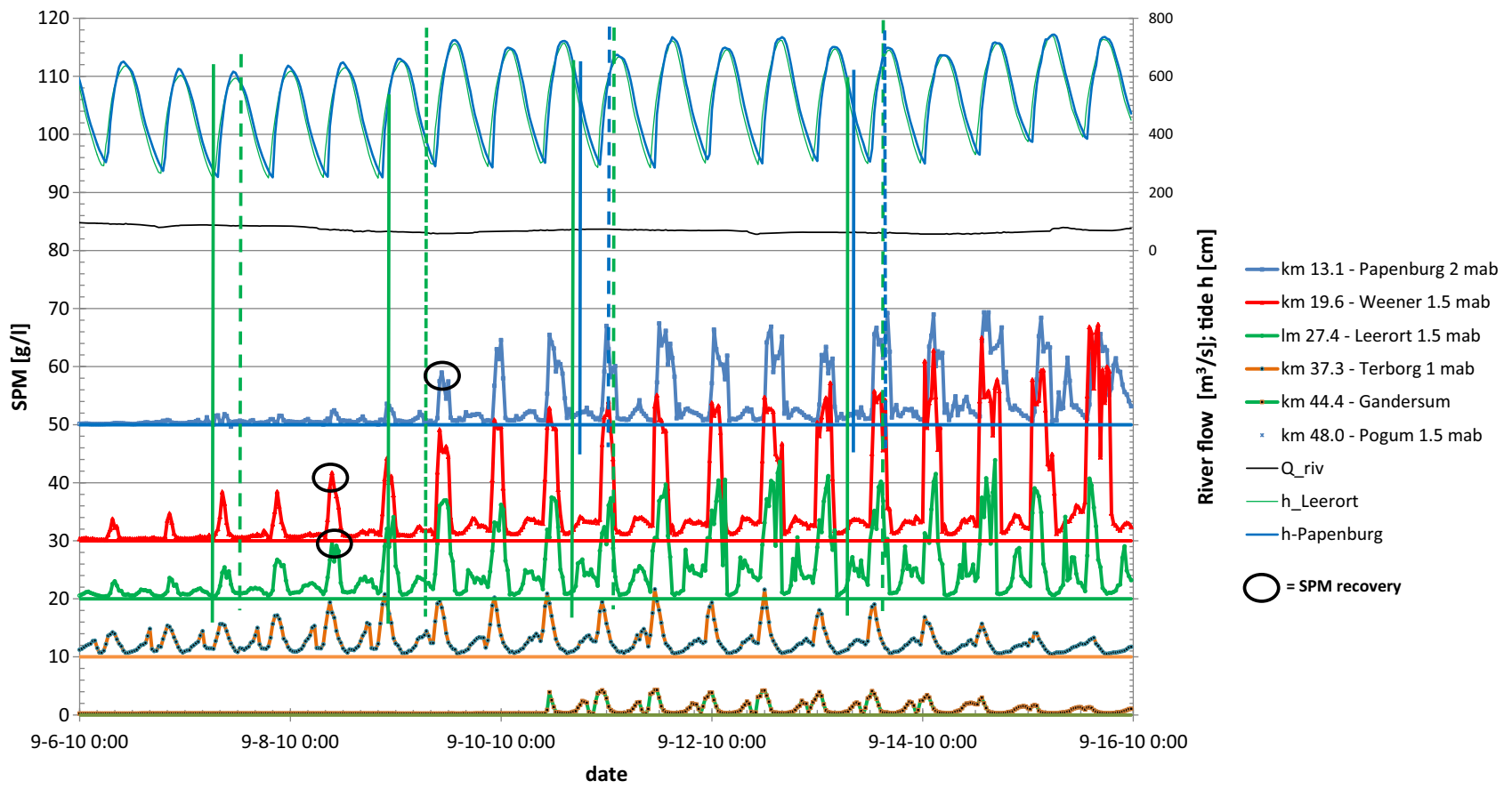

Fig. 22 SPM values at six stations along Ems River at phase III, i.e. mean river discharge $\left(70 \mathrm{~m}^{3} / \mathrm{s}\right)$. The lower six lines represent the measured SPM at the six stations in the legend-note that the SPM basis for each station is shifted by $10 \mathrm{~g} / \mathrm{L}$ for clarity of the graph. The

would occur on 8 September, 10:00 h, and at Papenburg on 9 September, 11:00 h. From Fig. 22, we find recovery when the flow velocity exceeds a critical value of $U_{\text {cr, }}=1.3-1.4 \mathrm{~m} / \mathrm{s}$. Of course, we would find higher values for $U_{\mathrm{cr}, \mathrm{r}}$ if we would increase the recovery SPM. Note that as soon as SPM values rise, this rise is again in phase with the onset of flood velocities.

Hence, our analyses suggest a hysteresis in the collapse and recovery of the SPM profile, as the critical peak flood velocity for collapse $U_{\mathrm{cr}, \mathrm{c}}$ amounts to $1-1.2 \mathrm{~m} / \mathrm{s}$ and the critical peak flood velocity for recovery $U_{\mathrm{cr}, \mathrm{r}}=1.3-1.4 \mathrm{~m} / \mathrm{s}$ (or higher). The likely explanation for this hysteresis is that the soft sediments gain some strength through consolidation, while resting on the river's bed. This would imply that recovery of the SPM profile requires erosion of that bed, instead of turbulent mixing. Also, some armouring may occur by sand washed downriver at high river flow (see next section).

Comparing Figs. 20 and 22, it takes about 7 days before the river flow has decreased below $100 \mathrm{~m}^{3} / \mathrm{s}$ (i.e. $\hat{u}_{\text {flood }} \approx 1.4-1.5 \mathrm{~m} /$ s, see Fig. 7) after its peak value on 30 August. SPM recovery to $10 \mathrm{~g} / \mathrm{L}$ takes about 17 tides after peak river flood at Leerort, 19 tides at Weener and 25 tides at Papenburg. Thereafter, stable SPM values require a few more days. This slow recovery is another indication for consolidation and strength development of the mud during the days of high river flow.

The second important observation from our analysis yields the relation between vertical mixing and horizontal transport. (almost horizontal) black line depicts the recovered river flow, and the two upper lines depict the tide at Leerort and Papenburg. Vertical lines are added to illustrate the timing of LWS (HWS) and the response of SPM, whereas black circles depict the flow rate at which SPM reaches $10 \mathrm{~g} / \mathrm{L}$.

SPM data at Terborg suggest down-estuary transport during ebb. However, none of the data shows an increase in SPM with increasing river flow in down-estuary monitoring stations, when SPM values further up-estuary decrease. Hence, we may conclude that the sediments are not washed downestuary during short-lived high river flow events. On the contrary, the data suggest that the sediments remain at place but are no longer mixed up to the level of the OBS sensors. Hence, the mud is there, but we do not see it.

Note that during elongated periods of high river flow, down-estuary transport is expected in that part of the Ems River where the conditions become ebb dominant, as discussed in the following.

The SPM response to varying river flow and spring-neap conditions is further illustrated through the variations in oxygen content measured at six levels over the water depth, carried out between 20 June and 6 July 2014, at $24.4 \mathrm{~km}$, Middelstenborgum, i.e. between Weener and Leerort (see Fig. 23). These measurements were carried out in the lower $3 \mathrm{~m}$ of the water column, with the upper sensor about $3 \mathrm{~m}$ below the low water surface. Spring tide was around 27-30 June. Note that this station is situated in that part of the Lower Ems River where SPM values are always very high at low river discharge (see Fig. 4).

First, the oxygen measurements after 1 July are discussed, i.e. after almost 3 weeks of low discharge of about $30 \mathrm{~m}^{3} / \mathrm{s}$ 


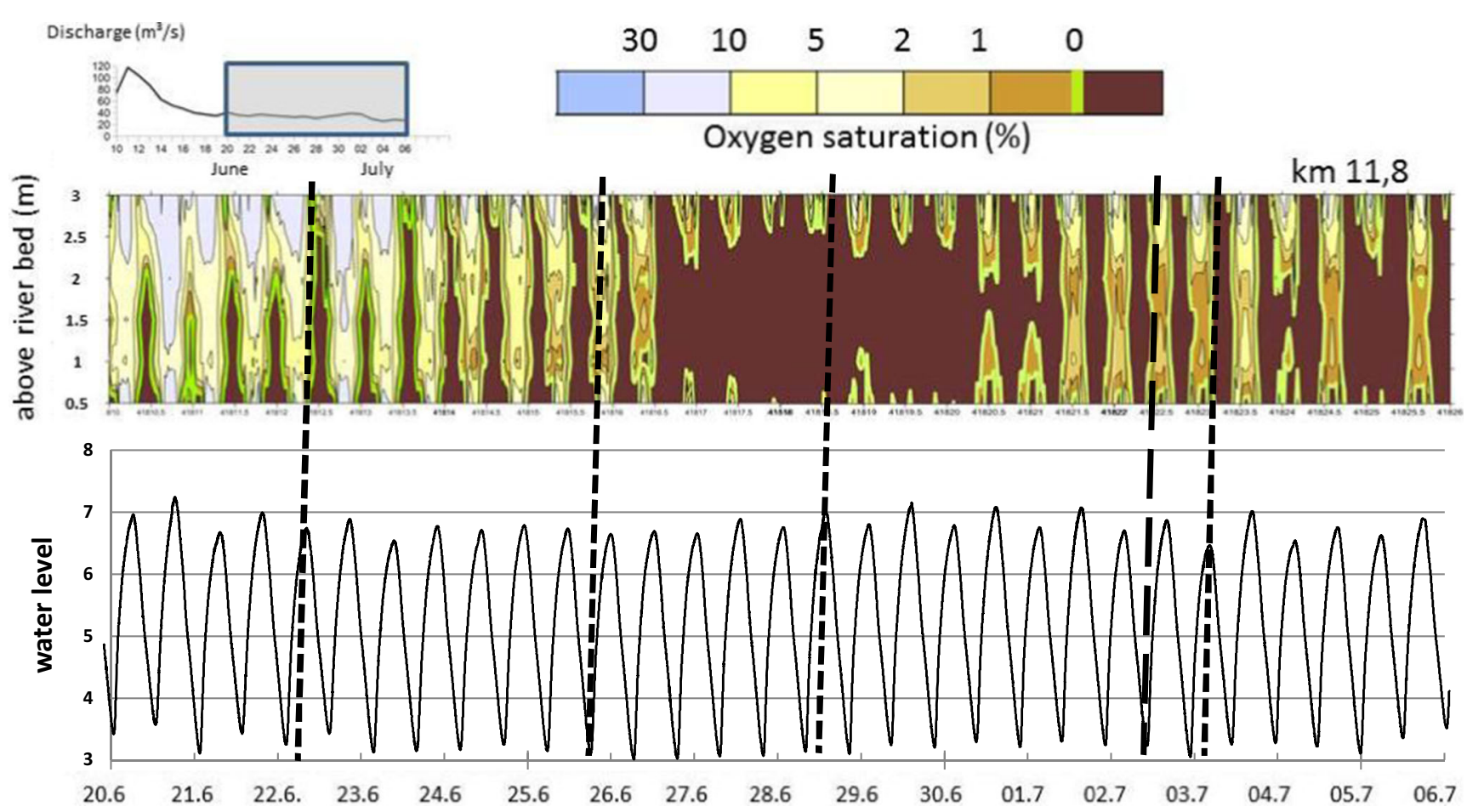

Fig. 23 Oxygen concentrations measured in June/July, 2014, at $24.4 \mathrm{~km}$ at six levels in the lower $3 \mathrm{~m}$ of the water column (local water depth at low water $\sim 6 \mathrm{~m}$ ). The water temperature in these lower $3 \mathrm{~m}$ varied between 17 and $21{ }^{\circ} \mathrm{C}$. The inset depicts the river flow during and prior to the

measurements, whereas the lower graph depicts the tidal range. As discussed before, spring-neap variations can be identified from the tidal water level variations. Vertical dashed lines are added to facilitate reading the graph

following the peak river discharge of $120 \mathrm{~m}^{3} / \mathrm{s}$. Oxygen levels vary from virtually zero during ebb to $1-2 \%$ during flood. These low values result from the high oxygen demand in the fluid mud layer, while the water column is highly stratified. The different values during flood and ebb can be understood from the degree of mixing. After LWS, oxygen-richer water from the upper part of the water column is entrained rapidly into the fluid mud layer, whereas this entrainment rate is smaller during ebb, as discussed earlier. Thus during ebb, less oxygen-rich water is entrained into the anoxic mud. Of course, the oxygen values at this station are also affected by advection from oxygen-poor water/mud from up-estuary during ebb and from down-estuary during flood.

During spring tide (27-30 June), more oxygen-depleted mud is mixed (higher) over the water column, and oxygen levels remain virtually zero throughout the tide, as oxygen- rich water entrained into the mud can no longer compete with the high oxygen demand within the mud.

At the beginning of the observational period, oxygen levels during flood are much higher. These higher levels can be explained from the reduction in mixing capacity at the higher river flow (see Fig. 20). However, SPM values still rise with accelerating tide, and oxygen-poor water is advected downestuary to the measuring stations. Thus, low-oxygen mud arrives from up-estuary during ebb.

Oxygen measurements at Terborg in the same period (Fig. 24) reveal oxygen concentrations between 10 and 30\%, decreasing rapidly at spring tide and showing oxygen depletion in the lower meter of the water column during ebb, because of down-estuary transport of oxygen-poor water. The high oxygen levels in the beginning of the observational period at the two stations (Figs. 23 and 24) suggest that oxygen-

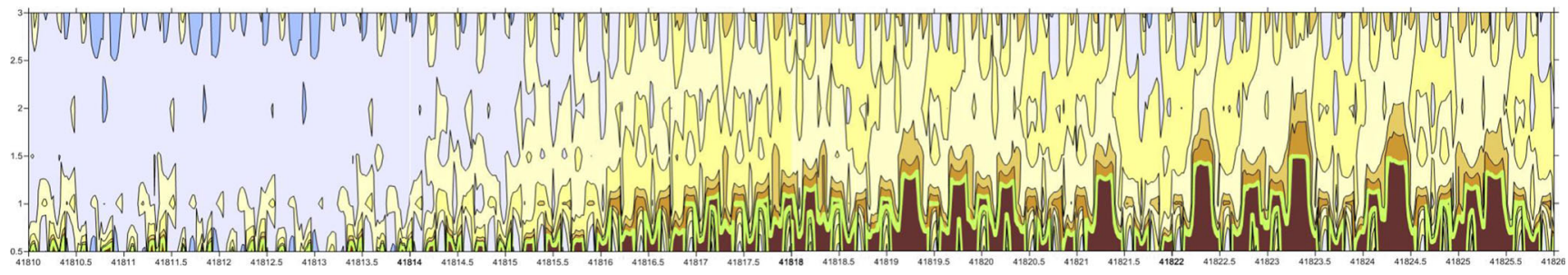

Fig. 24 Oxygen concentrations measured in June/July, 2014, close to Terborg at six levels in the lower $3 \mathrm{~m}$ of the water column (local water depth at low water $\sim 6 \mathrm{~m}$ ) from June 20 to July 6; for legend, river flow and tidal range, see Fig. 23 

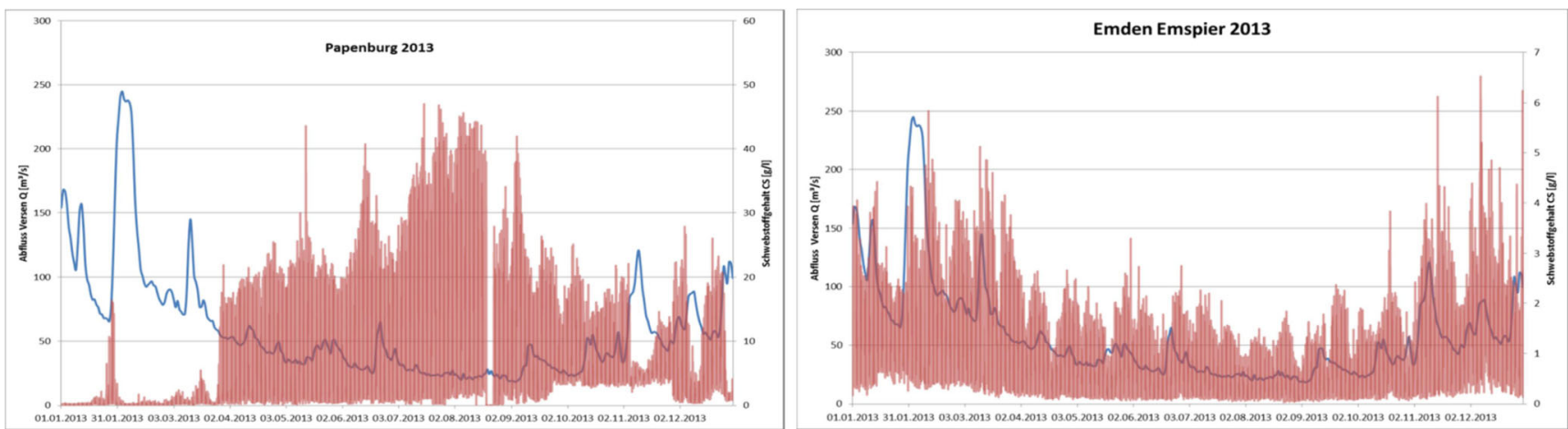

Fig. 25 Seasonal variations in river flow and SPM at Papenburg and Emden in 2013; note the different scales on the SPM-axes

poor water and mud are not transported down-estuary during high river flow, as postulated earlier.

\section{Effect seasonal variations in river flow}

Figure 3 presents the seasonal variations in SPM values measured at Papenburg, showing an inverse relationship between SPM values and river discharge. Figure 9 suggests that the hydrodynamic conditions at Papenburg become ebbdominant when the river discharge exceeds $90-130 \mathrm{~m}^{3} / \mathrm{s}$, depending on the definition used. On average, these flow rates are expected during about 4 months of the year (Fig. 3, though periods of lower discharge may also occur in these months). These observations are further illustrated Fig. 25, showing seasonal SPM variations on a more detailed scale. At first view,
Fig. 25 suggests that at high river flow, sediment is flushed down-estuary in the Lower Ems. However, this cannot be explained from a reversal in tidal asymmetry, as the river is always flood-dominant down-estuary of Terborg (Fig. 9). Also, at these larger river flows, saline water still enters the Lower Ems River, so that also the effects of estuarine circulation still induce a net up-estuarine transport. We postulate that the larger SPM values in the lower reaches of the river, during large river flows, i.e. mainly during winter, reflect a larger supply from the Ems-Dollard estuary and/or local bank erosion. High river flows generally coincide with bad weather and wind, and wind-induced waves in the very shallow and muddy EmsDollard estuary will mobilize fine sediments, which can then be transported into the Lower Ems River by the flood-dominant tidal asymmetry and estuarine circulation. Similarly, bad weather conditions may expose the river banks locally.
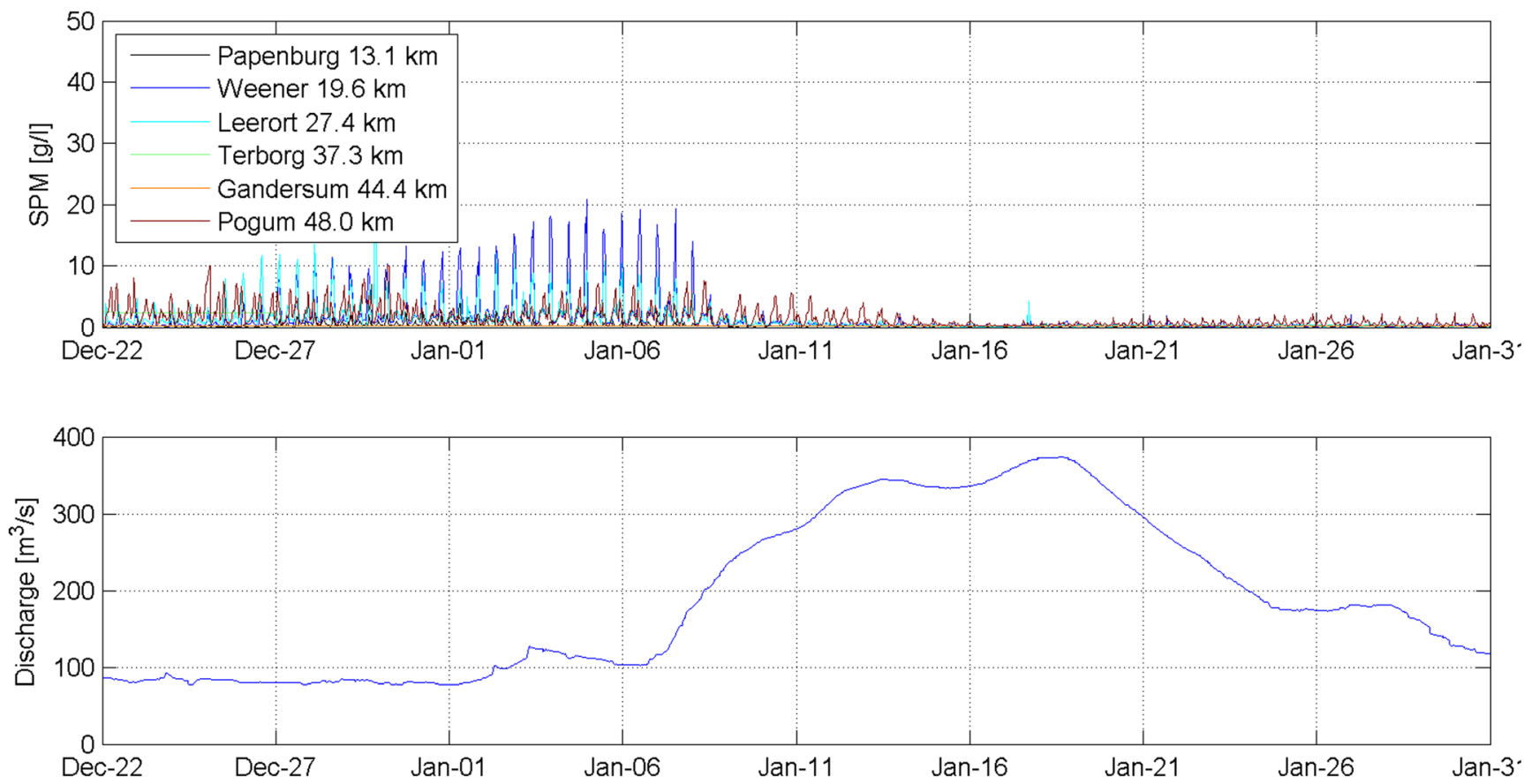

Fig. 26 Measured response of SPM values in 2010/2011 at high river discharges up to almost $400 \mathrm{~m}^{3} / \mathrm{s}$. Apart from one small peak at Leerort, the SPM signal collapses in the entire river 

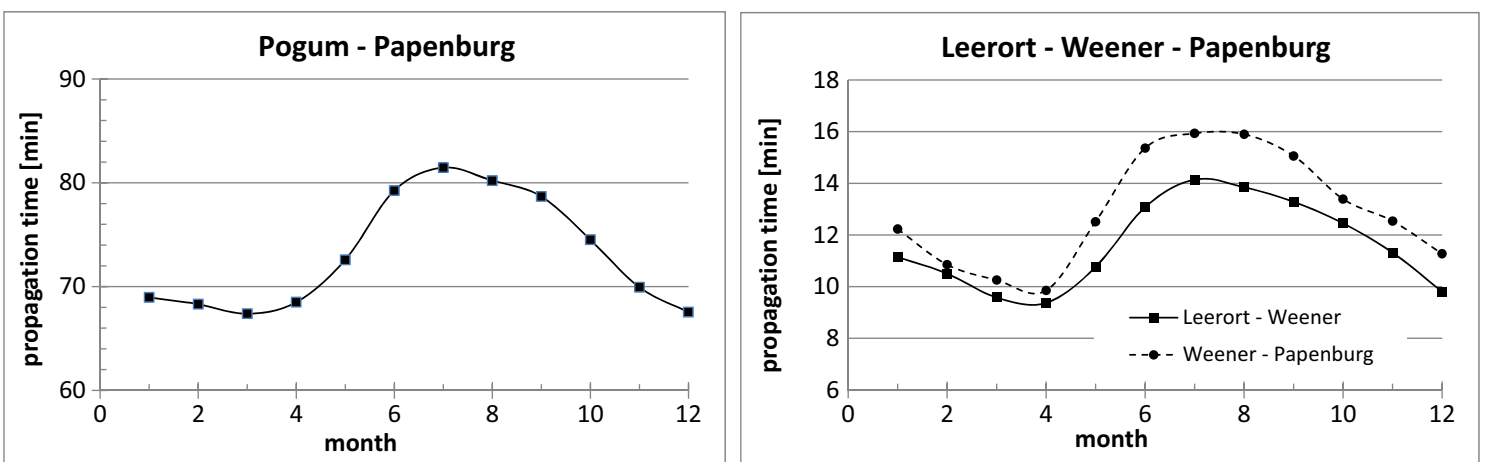

Fig. 27 Seasonal variations in measured propagation time of high waters along the Ems River

Therefore, we continue on our arguments in the three previous sections. It is likely that at very high river discharges, also the peak ebb velocity shall exceed $U_{\mathrm{cr}, \mathrm{c}}$; thus, that maximal mixing would occur during ebb, and sediment would be transported down-estuary. However, even at the highest river flow in our data series (January $2011, Q_{\text {riv }} \approx 400 \mathrm{~m}^{3} / \mathrm{s}, \hat{u}_{e b b}=1.5-2 \mathrm{~m} / \mathrm{s}$, see Fig. 26), no vertical mixing of SPM is observed during ebb-in fact, SPM values measured at Papenburg, Leerort and Weener were virtually zero. We do not have detailed data to explain this somewhat surprising observation. Therefore, we have to speculate that the inability of the strong ebb current to mix sediments over the water depth is caused by one or a combination of the following effects:
1. It is possible that all sediments have been washed out of the Ems. This is highly unlikely, as the records show that SPM values are high again only 1 month after this peak discharge (data not shown here).

2. Prior to the high river discharges in winter, the river discharge is high, but not extreme, and sediment is not entrained from the bed by the peak flood currents. The mud therefore gets time to consolidate, i.e. gain strength, and thereby, its erodibility is reduced.

3. After high flow events, sand is found on the river bed around Papenburg, which may armour the mud deposits, but only in the upper reaches of the river

4. The vertical velocity profile is more gentle during ebb than during flood, with stronger near-bed velocity gradients during flood (see also Held et al. 2013). Hence, near-

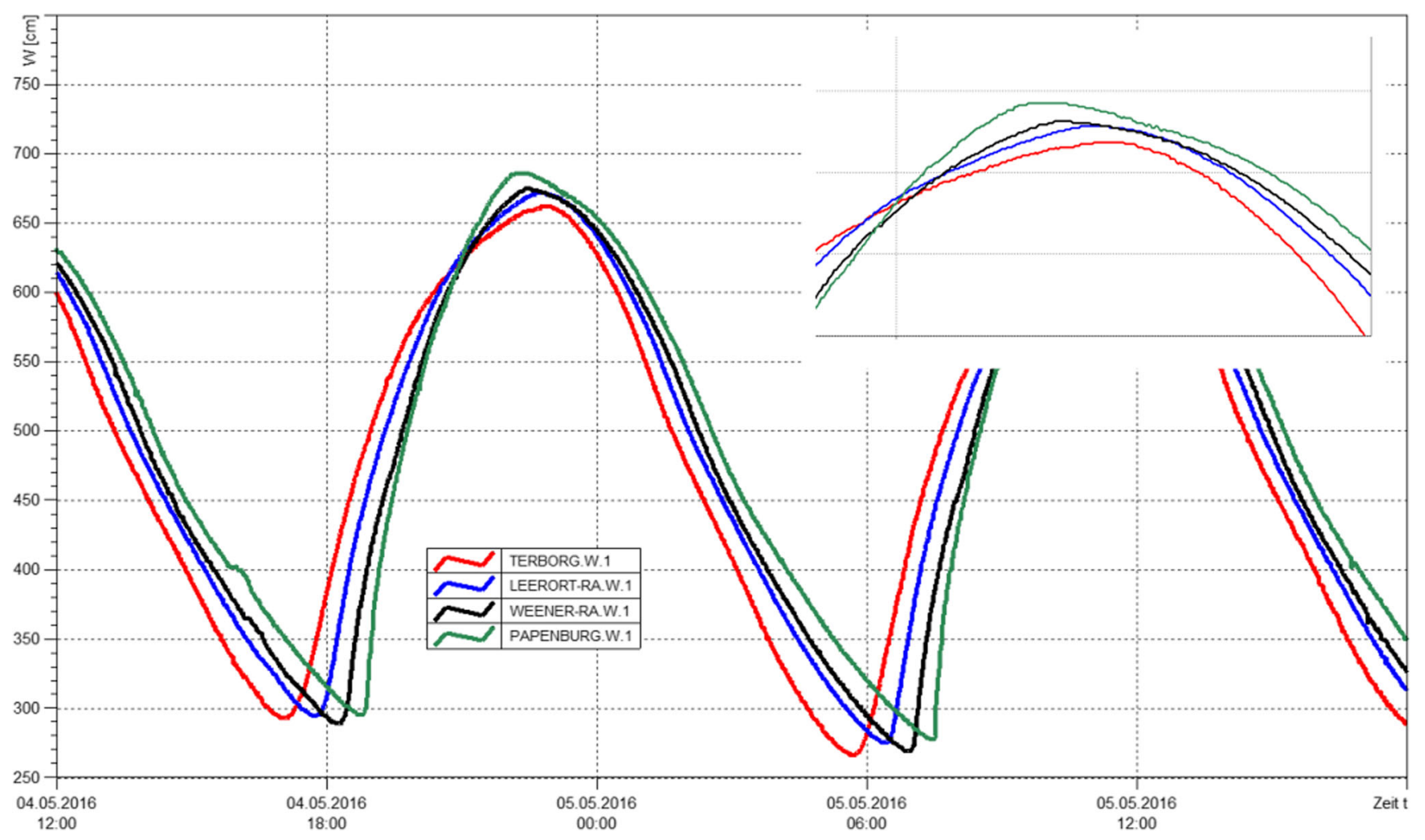

Fig. 28 Deformation of the tide in July 2014 


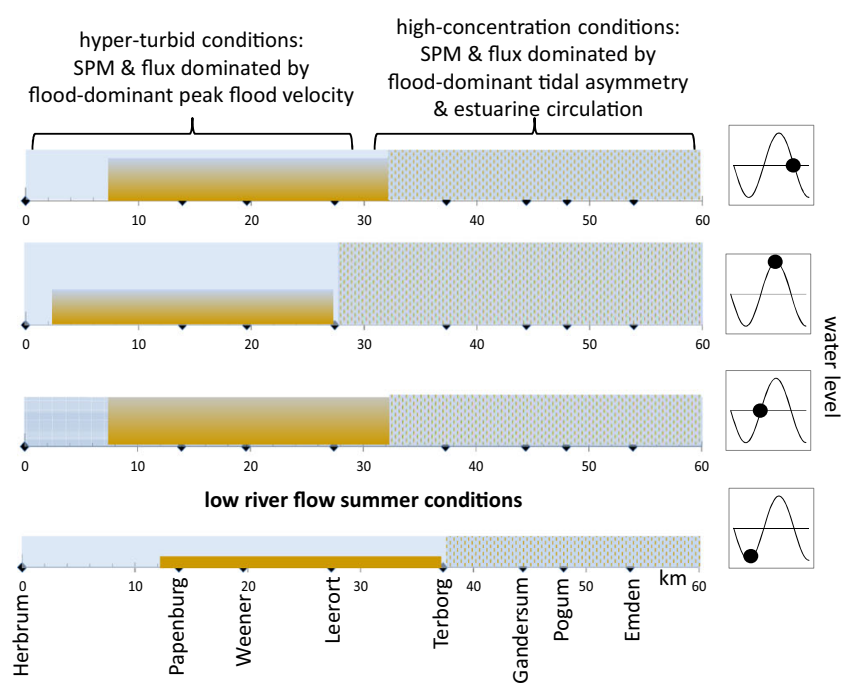

Fig. 29 Cartoon of SPM dynamics over a tidal cycle in the Lower Ems River during low (left panel) and high (right panel) river flows. The actual SPM dynamics are also affected by the spring-neap cycle. We have no

bed mixing is stronger during flood than during ebb. In other words, the strong ebb velocities may not be efficient mixers.

Next to the seasonal effects on SPM values, data reveal a seasonal effect on the propagation time of the tidal wave along the Lower Ems River, e.g. Fig. 27, with the larger propagation time in summer, when river flows are low and SPM values are high. This picture is consistent along the entire river. This behaviour is explained from three mechanisms related to the river discharge. First, higher river discharge increases the water depth in the river causing a larger propagation speed of the tidal wave. Second, with higher river discharge, less water from downstream is required for the water level to rise from LW to HW. Thirdly, during summer, SPM values are higher in the upper reaches of the river, reducing the effective hydraulic drag through stratification.

However, HW at Papenburg can occur before HW at stations further down-estuary, as shown in Fig. 28. This anomaly is always found when river flows exceeded about $30 \mathrm{~m}^{3} / \mathrm{s}$. Low water timing, however, is regular. We have analysed the timing of high and low waters with the Delft3D model but were not able to reproduce this anomaly in HW occurrences. We postulate that stratification of the water column and possibly subtleties in the geometry and bed composition (effective roughness) are the cause of these effects.

\section{Discussion and conclusions}

In this paper, we discuss the SPM dynamics in the hyperturbid Lower Ems River at four timescales, e.g.

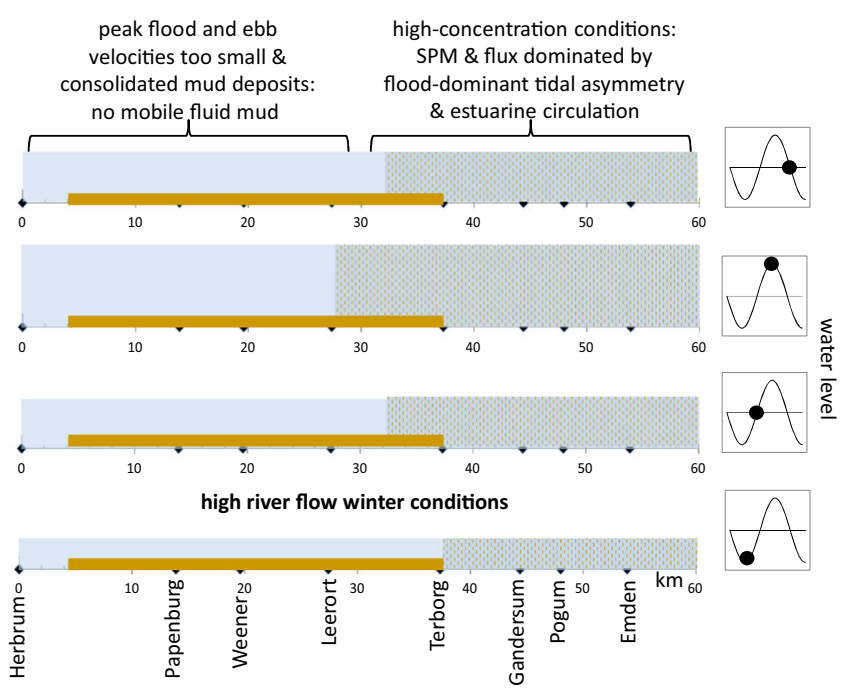

detailed information on the mud dynamics up-estuary of Papenburg, but this reach of the river is reported to be very muddy as well

1. Tidal timescale (semi-diurnal tide)

2. Timescale of the spring-neap cycle

3. Timescale of short-duration river floods in summer time

4. Seasonal variations

Our analyses are based on measured data of water levels, river discharge, SPM concentrations and salinity and flow velocities computed with a calibrated Delft3D model of the Lower Ems River. These data are available for 2009-2011 for multiple stations along the river, but we focus on the SPM dynamics at Papenburg, Weener and Leerort in the year 2010. Further, we have used measurements on oxygen saturation and acoustic measurements for sustaining our arguments further.

The data (e.g. field and model data) show that the Ems River is in a synchronic state, i.e. high water (HW) and high water slack (HWS), and low water (LW) and low water slack (LWS) occur at almost the same time, whereas the tidal amplitude is almost constant along the river. Such synchronic conditions are typical for rivers with a converging plan form and very low hydraulic drag. Towards the head of the estuary, also reflection of the tide against the weir at Herbrum affects the tidal propagation.

The tide is highly asymmetric during low river flows, and the flood velocity peaks shortly after LWS. At low river flows, flood velocities peak at about $1.5 \mathrm{~m} / \mathrm{s}$, while ebb velocities measure around $1 \mathrm{~m} / \mathrm{s}$; the ebb period is therefore about $50 \%$ longer than the flood period. With increasing river discharge, flood velocities decrease, whereas ebb velocities increase. As a result, the tidal asymmetry decreases with increasing river discharge. As the Lower Ems River has an exponentially converging plan form, the decrease in tidal asymmetry with increasing river discharge reduces in downestuary direction. This decrease in asymmetry follows an 
exponential trend, identical to the exponential convergence length of the river's plan form.

Our observations suggest a very persistent existence of a pool of fluid/soft mud, found in summer time somewhere between Papenburg (or further up-estuary where we have no data) and Terborg. Somewhere between Terborg and Gandersum, SPM values drop sharply, though the suspended sediment concentrations still reach values of many grams per litre. This pool of fluid mud is entrained rapidly into the water column during flood, when peak flood velocities exceed a critical value of about $1-1.1 \mathrm{~m} / \mathrm{s}$, and the mud is transported up-estuary with the flood tide. This mixing is governed by the entrainment of SPM-poor, but oxygen-rich water into the turbulent turbid layer. Around HWS, suspended sediment settles slowly, and thereafter, the dense mud suspension migrates down-estuary with the ebb tide. Around LWS, most of the sediment settles and the cycle repeats. These observations strongly suggest that it is the peak flood velocity that determines the amount of fines brought into suspension. Our analyses suggest that the rapid mixing at the onset of flood occurs when the internal flow becomes supercritical. As a result, SPM response to the spring-neap cycle is significant, owing to the $20 \%$ higher/lower tidal velocities during spring/neap.

We have analysed the SPM dynamics in response to shortduration peaks in river discharge in summer time, i.e. when the mean river discharge is generally low. When the river discharge exceeds $150 \mathrm{~m}^{3} / \mathrm{s}$, SPM values collapsed at Papenburg, and SPM collapse at Weener and Leeroort was observed at around $240 \mathrm{~m}^{3} / \mathrm{s}$. The data do not show any increases in SPM values down-estuary of the collapsing stations; hence, down-estuary migration of the mud with the river flow is unlikely or small during these short-duration river peaks.

However, in terms of peak flood velocities, SPM collapse at these three stations occurs almost at the same conditions, i.e. when the peak flood velocity becomes smaller than a critical value $U_{\text {cr,c }}$, which amounts to about $1-1.2 \mathrm{~m} / \mathrm{s}$. Further to our previous discussion, this observation suggests that SPM collapse occurs when, locally, the internal flow becomes subcritical. As the effects of river flow on peak flood velocity decrease in downestuary direction, SPM collapse starts in the upper parts of the river, migrating down-estuary with increasing river discharge.

The SPM records suggest further that SPM recovery occurs with decreasing river flow when the flow velocity exceeds another critical value $U_{\text {cr,r }}$, which amounts to about 1.3$1.4 \mathrm{~m} / \mathrm{s}$. This value is larger than $U_{\text {cr,c. }}$. Likely, this hysteresis is the result of some strength development of the mud, while sitting on the river bed: apparently, it takes time to erode/ loosen the mud again to Newtonian conditions. Possibly armouring by sandy deposits, brought by the river, plays a role as well. Hence, we conclude that the collapse and subsequent recovery of SPM concentrations with increasing/ decreasing river discharge are a local effect; i.e. the pool of fluid mud is temporarily not remixed over the water column.
Because peak-flood velocities become too small, the mud cannot be mixed (entrained) up to the OBS sensor. The mud is still there, but the sensor does not see the mud anymore.

Further to this analysis, the seasonal variation in SPM can be explained. During the high river flows, generally prevailing in winter, the pool of fluid mud cannot be entrained into the water column, owing to too small flood velocities during elongated periods of time. Then, the fluid mud consolidates and gains strength. This picture is confirmed by observations during a peak river discharge of $400 \mathrm{~m}^{3} / \mathrm{s}$, when velocities locally exceed $1.5-2 \mathrm{~m} / \mathrm{s}$. Yet, SPM values remain virtually zero in the upper reaches of the river.

In our analyses, we hardly touched upon the SPM dynamics in the lower reaches of the Lower Ems River. However, many studies show that in these lower reaches, SPM dynamics are governed by tidal asymmetry and estuarine circulation (e.g. Talke et al. 2007; Krebs and Weilbeeer 2008; Winterwerp 2011) while also asymmetry in floc formation/ size may play a role (Winterwerp, 2011). As SPM concentrations are high, also asymmetries in vertical mixing play a role (internal asymmetry).

These observations suggest that the SPM dynamics in the Lower Ems River depict a transition in driving forces and behaviour (see Fig. 29). This transition would occur around Terborg. Down-estuary of Terborg, the river is in a so-called high-concentration state with profound interactions between SPM and the turbulent flow field. Horizontal SPM fluxes are governed by tidal asymmetry and estuarine circulation. This part of the river is always flood-dominant, except possibly at extreme river flows, much larger than studied in this paper. The sediment originates from the Ems-Dollard estuary, where it is mobilized by waves and tidal currents, whereas human activities (dredging and dumping) play a role as well. Observed increases in SPM with increasing river flow cannot result from flushing and/or changes in tidal asymmetry, as the effects of river flow on advection rapidly decrease down-estuary. Hence, we postulate that these increases result from a simultaneous increase in wave activity with increasing river flow (rain and wind come often together in our temperate climate).

Up-estuary of this transition (Terborg), the estuary is in a hyper-turbid state, induced by a large pool (25-30 km long) of soft/fluid mud during low river flows. SPM values are governed by the peak flood velocity. When peak flood velocities exceed a critical value, mud is rapidly mixed over the water column. This critical value seems to be related to internal critical conditions. The horizontal SPM flux is mainly governed by internal asymmetry; i.e. during flood, SPM is mixed further over the water column than during ebb and hence experiences larger velocities. Vertical mixing is governed by entrainment processes, pumping (oxygen-rich) water into the accelerating, but anoxic mud layer. With increasing river flow, peak flood velocities decrease, and the 
soft/fluid mud layer can no longer be sufficiently mixed, thus stays on the riverbed and gains strength through consolidation. The soft/fluid mud layer, however, does not or slightly migrate down-estuary. At very high river flows in winter, also ebb velocities can become large, but SPM concentrations do not increase. Of course, the mud layer can then be eroded by classical surface erosion - these eroded sediments will be flushed down-estuary, but not much further than around Terborg, as there flood-dominant tidal asymmetry and estuarine circulation prevail, trapping the sediments within the river.

Our study shows the fertility of combining field observations with numerical model results, even when that model does not resolve all details of the flow field. In particular, it appeared possible unravelling the effects of tide and river flow, which of course act jointly on the SPM dynamics. Yet, many conclusions from our study should be further sustained with more detailed and elongated measurements of the flow field and the vertical SPM distribution, while also further model development will enhance our understanding of the relevant physical processes. In particular, we think of the consolidation behaviour of the sediments during periods of non-mixing, the variations in Richardson number for quantifying the role of stratification, sediment fluxes through the river during short-duration floods along the river and possibly the role flocculation on the SPM dynamics.

Acknowledgements Most data analysed in this paper have been collected by the German Wasserschiffsamt (WSA) and the Niedersächsishce Landesbetrieb für Wasserwirtschaft, Küsten und Naturschutz (NLWKN), which is gratefully acknowledged. SES based data were collected in a project, funded by the Deutsche Forschungsgemeinschaft as part of RCOM (no 0404) / MARUM Bremen and the Senckenberg Institute who provided the ship time. Also, we like to acknowledge two anonymous reviewers for their detailed comments.

\section{Appendix}

\section{Synchronicity of the Ems River}

The assumption of synchronicity of the Ems River is one of the central premises in our paper. The tidal data presented in Figs. 5 and 6 suggest indeed that the Ems River is synchronous; i.e. low water (LW) and low water slack (LWS) and high water (HW) and high water slack (HWS) occur at the same time, whereas the tidal range is almost constant along the river. Given the limited velocity data, we need further evidence that synchronicity of the Ems River is the common feature and not limited to the two brief surveys presented in Figs. 5 and 6.

In this appendix, we present further evidence on the synchronicity of the Ems River, consisting of
1. An analysis of measured salinities in relation to water level data

2. Comparison of computed tidal water level data and tidal velocities

3. Decomposition of water level data into tidal components in relation to the river flow

Details of the analyses below are given in Hendriks (2015). The first evidence for synchronicity is provided by the measured salinity distribution, as the phase difference between HW and maximum salinity $S_{\max }$ and between LW and $S_{\min }$ provides a good proxy for the phase difference between HW and HWS, and LW and LWS, respectively, assuming that $S_{\max }$ occurs at HWS and $S_{\min }$ at LWS. An example of the phase differences $\Delta$ for Leerort is presented in Fig. 30. Table 4 presents the results of our analysis for these differences $\Delta$ for the year 2010, where $\mu_{\Delta}=$ mean phase difference and $\sigma_{\Delta}=$ standard deviation of that difference, showing the mean phase difference in the upper $40 \mathrm{~km}$ of the Ems River, i.e. beyond Terborg, amounts to a few $10 \mathrm{~min}$. Note that the salinity distribution is affected by salinity-induced (and SPMinduced!) density currents and therefore is generally ahead of slack water occurrence, enhancing the actual phase lag.

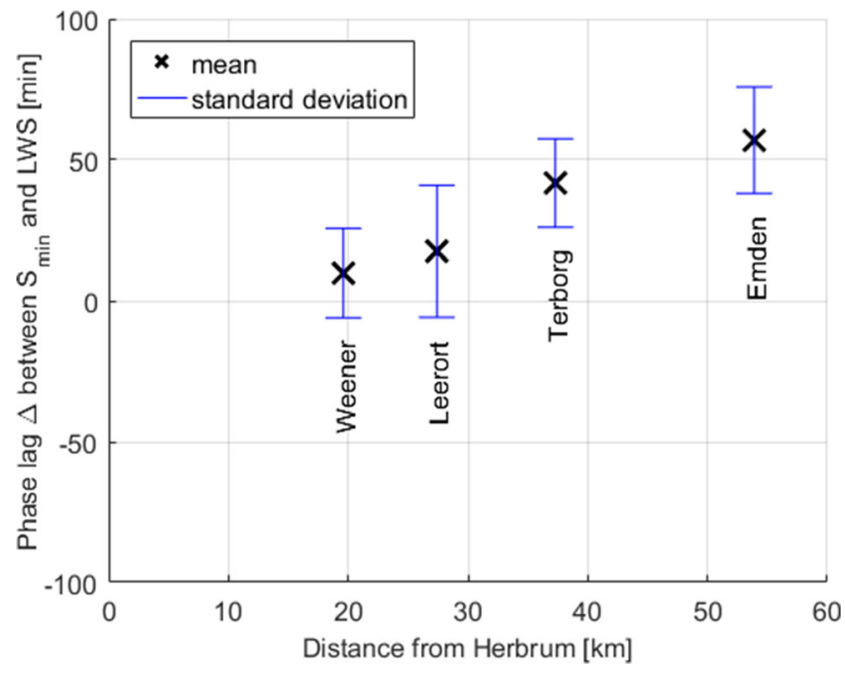

Fig. 30 Phase lag between measured low water and measured $S_{\min }$

Table 4 Phase difference between minimum and maximum measured salinities and low and high water, respectively, for 2010 , mean value $\mu_{\Delta}$ and standard deviation $\sigma_{\Delta}$

\begin{tabular}{lllll}
\hline & $\begin{array}{l}\text { Phase lag } \Delta=S_{\min }-\mathrm{LW} \\
(\mathrm{min})\end{array}$ & $\begin{array}{l}\text { Phase lag } \Delta=S_{\max }-\mathrm{HW} \\
(\mathrm{min})\end{array}$ \\
\hline & $\mu_{\Delta}$ & $\sigma_{\Delta}$ & $\mu_{\Delta}$ & $\sigma_{\Delta}$ \\
Emden & 57 & 19 & 51 & 15 \\
Terborg & 42 & 16 & 6 & 15 \\
Leerort & 18 & 23 & 20 & 19 \\
Weener & 10 & 16 & -26 & 59 \\
\hline
\end{tabular}


Note that though Table 4 (A.1) reflects the results of analysing almost 3 months of data (Weener 3 weeks because of high river flow), the results are typical for the entire observational period.

Next, we run the calibrated Delft3D model described in the main text of this paper. Figure 31 pre- sents some typical results, showing a phase difference between LW and LWS and between HW and HWS of a few minutes. Also, for other simulations, at high and low river flows, similar results were predicted with Delft3D.
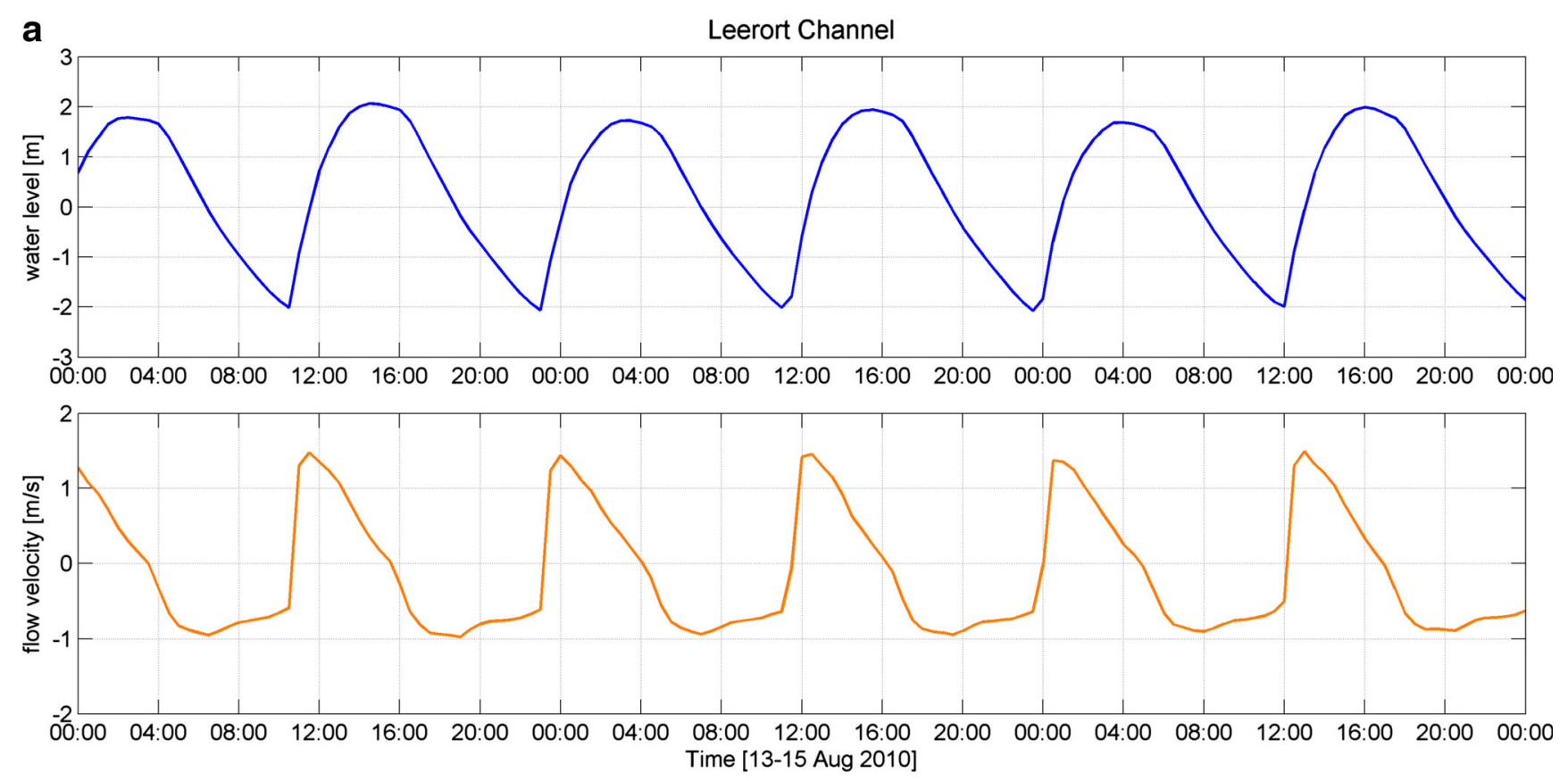

b Papenburg Channel
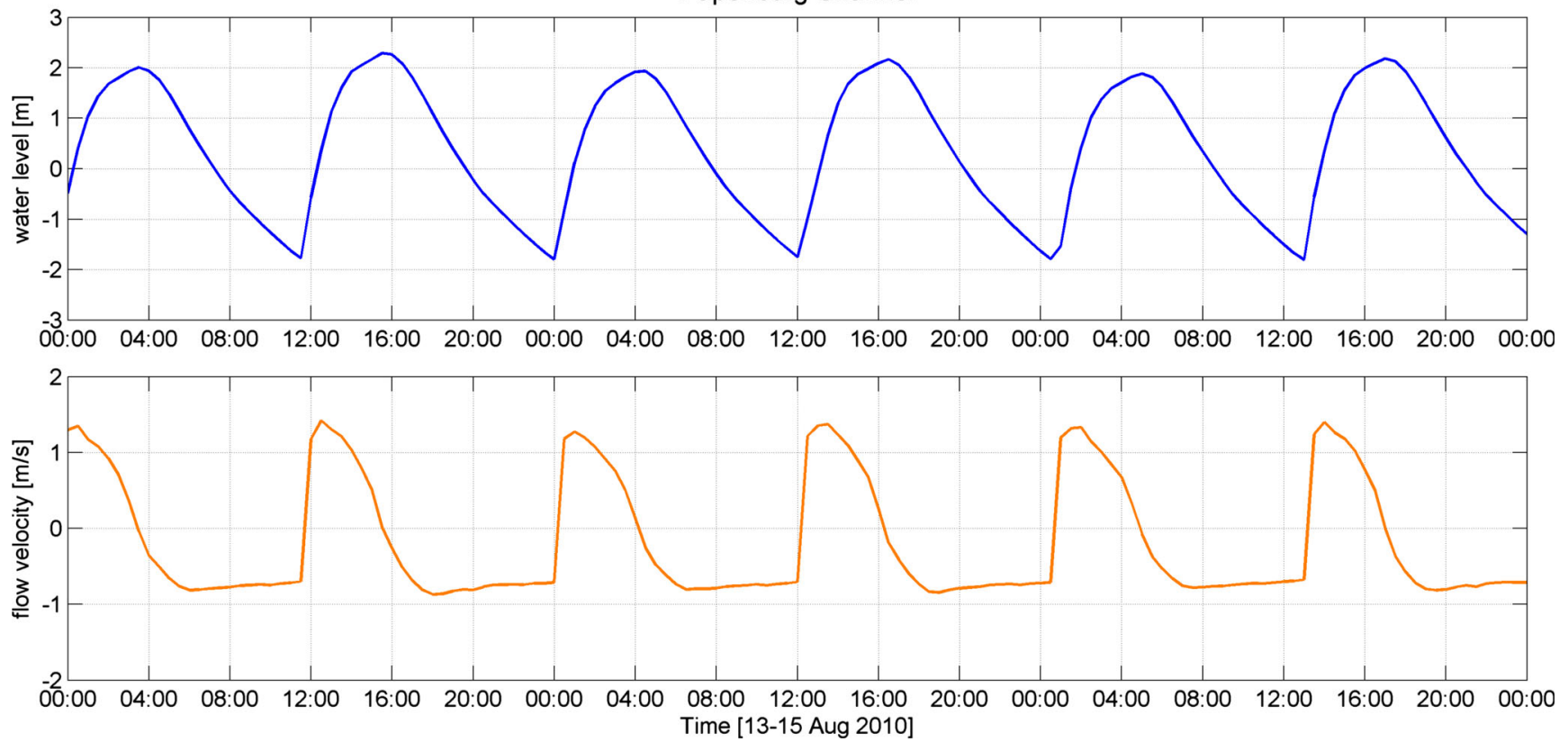

Fig. 31 Computed water level and flow velocity at Leerort (upper panel) and Papenburg (lower panel), showing near synchronicity of LW and LWS, and HW and HWS 
Finally, we have carried out a tidal analysis of the measured water levels for the year 2010, for all stations available. From these components, we reconstructed the astronomical tide for that year at these stations and then determined the difference between this astronomical prediction and the actual measurements, which we refer to as the residual. Note that the tidal components obtained from the tidal analysis reflect amplification of the tide by the reduced effective hydraulic drag induced by the high SPM values and fluid mud in the river. Then, we subtracted the residual found at Knock from the residual at all other stations in the Ems River to correct for seaborne disturbances. Hence, as an example, the residual at Weener minus the residual at Knock, as presented in Fig. 32, should reflect disturbances induced within the river itself, e.g. by the river flow. Figure 32 shows that the residual is small, except for some strange spikes, which are attributed to the closing of the Ems' storm surge barrier. However, if we compare the residual with the river flow, we observe that if there is any relation between the residual and peaks in river flow, it is an amplification of the tide; i.e. tidal amplitude increases with river flow.

If the fine sediments would be washed out of the river at high river flow, we expect an increase in effective hydraulic drag, hence damping of the tide, thus negative values of the residual. On the contrary, the observed small amplification of the tide at high river flow should be attributed to the role of the river flow on that amplification. Other irregularities in the residual cannot be explained from variations in river flow. Hence, it can be concluded that the sediment-induced reduction in effective hydraulic drag remains persistent throughout the year. In other words, the river remains in a synchronous state as drag remains low.

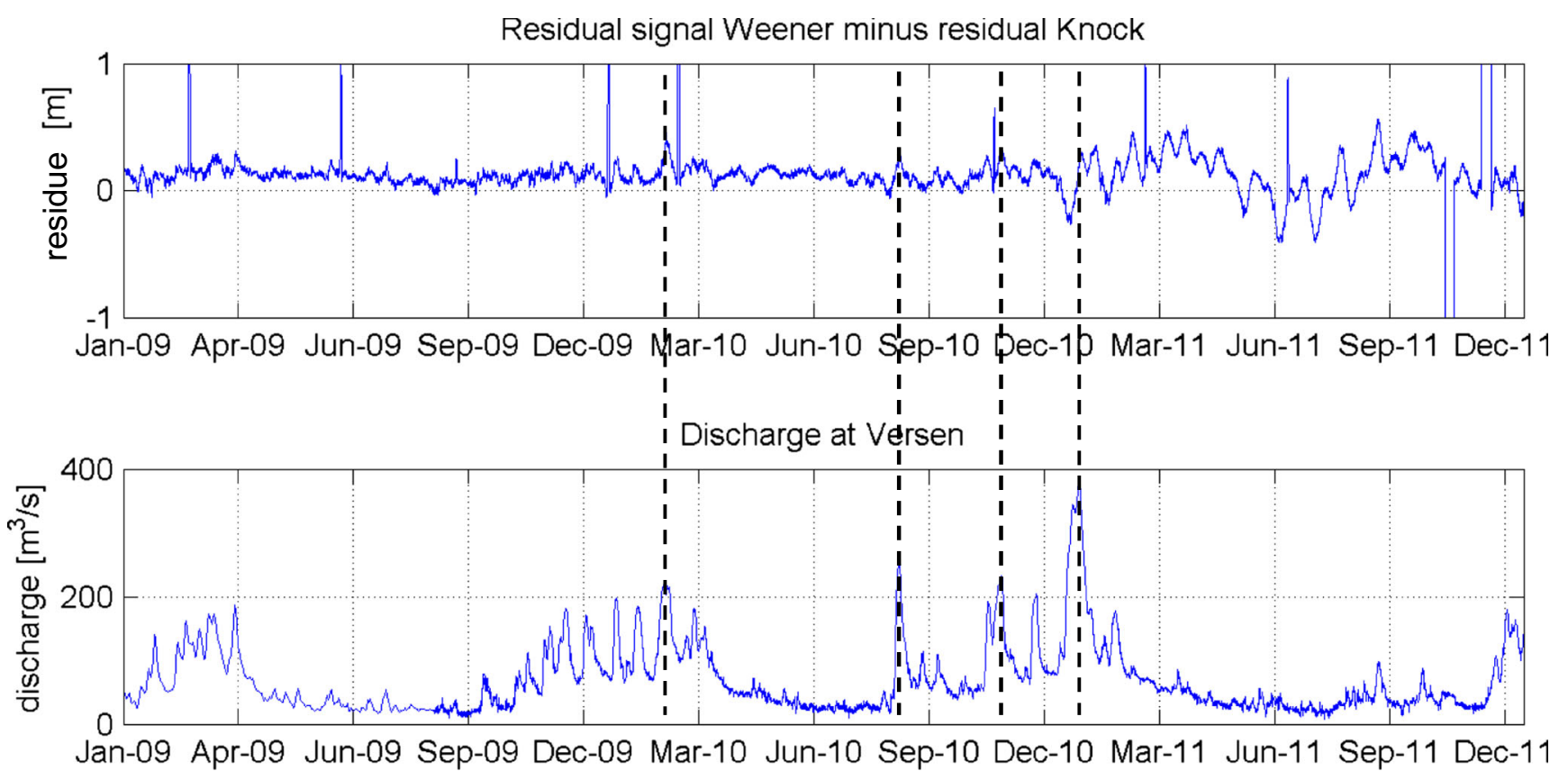

Fig. 32 Difference between measured tidal elevation and astronomical tide at Weener, corrected for seaborne disturbances at Knock in conjunction to the variation in fresh water flow

These analyses all suggest that the Ems River is in a synchronous state and remains so throughout the year. This conclusion also suggests that the majority of the fine sediments in the river are not washed out of the system but continue reducing the effective hydraulic drag in the river. Hence, we assume in the hyper-turbid part of the river that HW and HWS, and LW and LWS occur at the same moment, i.e. $t_{\mathrm{HW}}=t_{\mathrm{HWS}}$ and $t_{\mathrm{LW}}=t_{\mathrm{LWS}}$, respectively. 
Open Access This article is distributed under the terms of the Creative Commons Attribution 4.0 International License (http:// creativecommons.org/licenses/by/4.0/), which permits unrestricted use, distribution, and reproduction in any medium, provided you give appropriate credit to the original author(s) and the source, provide a link to the Creative Commons license, and indicate if changes were made.

\section{References}

Bruens AW, Winterwerp JC, Kranenburg C (2012) Physical and numerical modeling of the entrainment by a high-concentration mud suspension. ASCE, J Hydraul Eng 138(6):479-490

De Jonge VN, Schuttelaars HM, van Beusekom JEE, Talke SA, de Swart HE (2014) The influence of channel deepening on estuarine turbidity levels and dynamics, as exemplified by the Ems estuary. Estuar Coast Shelf Sci. doi:10.1016/j.ecss.2013.12.030

Dronkers J (2005) Dynamics of coastal systems. World Scientific, Advanced Series on Ocean Engineering-Volume 25

Friedrichs CT (2010) Barotropic tides in channelized estuaries. In: ValleLevinson A (ed) Contemporary issues in estuarine physics. Cambridge University Press, Cambridge, pp 27-61

Groen P (1967) On the residual transport of suspended matter by an alternating tidal current. Neth J Sea Res 3(4):564-574

Habermann C (2006) Einfluss von Unterhaltungsbaggerungen auf die Schwebstoffdynamik der Unterems. BfG-Bericht 1488, Koblenz

Held P, Schrottke K, Bartholomä A (2013) Generation and evolution of high-frequency internal waves in the Ems estuary, Germany. J Sea Res 78:25-35

Hendriks HCM (2015) Hyper-turbid conditions in the River Ems. Deltares \& TU Delft internship report

Krebs M, Weilbeer H (2008) Ems-Dollart-Estuary. Die Küste, Band 74

Le Hir P (1997) Fluid and sediment 'integrated' modeling application to fluid mud flows in estuaries. Cohesive Sediments. $4^{\text {th }}$ Nearshore and Estuarine Cohesive Sediment Transport Conference INTERCOH '94

Lesser GR, Roelvink JA, van Kester JATM, Stelling GS (2004) Development and validation of a three-dimensional morphological model. J Coast Eng 51:883-915

Papenmeier S, Schrottke K, Bartholomä A, Flemming, BW (2013) Sedimentological and rheological properties of the water-solid bed interface in the weser and ems estuaries, north sea, Germany: Implications for fluid mud classification. J Coast Res 29 (4):797-808

Schrottke K, Becker M, Bartholomä A, Flemminga BW, Hebbeln D (2006) Fluid mud dynamics in the Weser estuary turbidity zone tracked by high-resolution side-scan sonar and parametric subbottom profiler. Geo-Mar Lett 26(3):185-198

Schrottke K, Bartholomä A (2008) Detailed insight in estuarine suspended matter dynamics using high-resolution hydro-acoustics. Workshop: use of ultrasound in the hydrometry: new techniquenew applications? FgHW/DWA, 3-4 June 2008, Koblenz, (Germany), p. 75-82

Talke SA, de Swart HE, Schuttelaars HM (2007) Feedback between residual circulation and sediment distribution in highly turbid estuaries: an analytical model. Cont Shelf Res. doi:10.1016/j.csr.2007.09.002

Van Leussen W (1994) Estuarine macroflocs - their role in fine-grained sediment transport. PhD-thesis, Utrecht University, The Netherlands

Van Maren DS, Winterwerp JC, Vroom J (2015) Fine sediment transport into the hyper-turbid lower Ems River: the role of channel deepening and sediment-induced drag reduction. Ocean Dyn 65:589-605. doi:10.1007/s10236-015-0821-2

Van Maren DS, Oost AP, Wang ZB, Vos PC (2016) The effect of land reclamations and sediment extraction on the suspended sediment concentration in the Ems estuary. Mar Geol 376:147-157. doi:10. 1016/j.margeo.2016.03.007

Wang L (2010) Tide driven dynamics of subaqueous fluid mud layers in turbidity maximum zones of German estuaries. Am Fachbereich Geowissenschaften Der Universität Bremen, PhD-thesis

Winterwerp JC, Cornelisse JM, Kuijper C (1992) A Laboratory study on the behaviour of mud from the Western Scheldt under tidal conditions. Proceedings of the Workshop on Nearshore and Estuarine Cohesive Sediment Transport, April 1991, St. Petersburg, Florida, USA, in Coastal and Estuarine Studies Series, AGU, 42:295-313

Winterwerp JC (2001) Stratification of mud suspensions by buoyancy and flocculation effects. J Geophys Res 106(10):22,559-22,574

Winterwerp JC, Van Kesteren WGM (2004) Introduction to the physics of cohesive sediment in the marine environment. Elsevier, Developments in Sedimentology, 56

Winterwerp JC (2006) Stratification effects by fine suspended sediment at low, medium and very high concentrations. Geophys Res 111(C05012):1-11

Winterwerp JC (2011) Fine sediment transport by tidal asymmetry in the high-concentrated Ems River. Ocean Dyn 61(2-3):203-216. doi:10. 1007/s10236-010-0332-0

Winterwerp JC, Wang ZB (2013) Man-induced regime shifts in small estuaries-I: theory. Ocean Dyn 63:1279-1292. doi:10.1007/ s10236-013-0662-9

Winterwerp JC, Wang ZB, van Braeckel A, van Holland G, Kösters F (2013) Man-induced regime shifts in small estuaries-II: comparison of rivers. Ocean Dyn 63:1293-1306. doi:10.1007/s10236-0130663-8 